\title{
The proeutectoid cementite transformation in steels
}

\section{G. Spanos*1 and M. V. Kral ${ }^{2}$}

A comprehensive, critical, and up to date review is presented for the proeutectoid cementite transformation in steels. It is believed that many of the new findings, features, and concepts presented here for this classic phase transformation in steels serve as a model which may be more broadly applicable to test against many other phase transformations systems as well. There were a number of early investigations of cementite morphology, and this review considers those early results in light of many newer studies that provide critical new insight into cementite morphologies in both two and three dimensions. A number of different orientation relationships (ORs) between proeutectoid cementite and the austenite matrix from which it forms have been reported in the literature, in some cases leading to confusion, and they are critically evaluated here, as are the habit plane, growth direction, and interfacial structure of various morphologies of proeutectoid cementite. Quantitative experimental and theoretical investigations of the growth kinetics of the proeutectoid cementite transformation are considered next, and the nucleation site of proeutectoid cementite in austenite is also discussed in some detail. This review considers all of these issues in a critical way in which differences, commonalities, important features, and redundancies are sorted out, in order to present a unified picture that will add some clarity to this subject. The different features and issues of this transformation that are considered in detail throughout this review are finally brought together in a comprehensive way in the last major section of this paper on 'Formation mechanism(s) of proeutectoid cementite', in order to provide a complete, modern view of the formation of proeutectoid cementite from austenite. To the best knowledge of the present authors, before this review a thorough assessment of this classic phase transformation in steels had not been undertaken since 1962, when Professor Hubert I. Aaronson covered this topic in a section of the book entitled 'The Decomposition of Austenite by Diffusional Processes.. ${ }^{1}$ In large part due to a number of ground breaking new findings on the proeutectoid cementite transformation since then (particularly in the last decade), it is very timely for a new review on this topic.

Keywords: Cementite, Proeutectoid, Three dimensional microstructure, Phase transformations, Steels

\section{Introduction}

The proeutectoid cementite transformation has been studied in some detail for nearly 80 years, often as a model for solid state phase transformations. Building upon earlier work, more recent investigations (within about the last decade) have employed more advanced experimental techniques to elucidate many details and

\footnotetext{
${ }^{1}$ US Naval Research Laboratory, Code 6355, Materials Science and Technology Division, 4555 Overlook Ave., SW, Washington, DC, 203755000 ,US

${ }^{2}$ University of Canterbury, Department of Mechanical Engineering, Private Bag 4800, Christchurch, New Zealand

*Corresponding author, email george.spanos@nrl.navy.mil
}

refine some key concepts about this model phase transformation.

Proeutectoid cementite was first observed more than 100 years ago by Sorby in $1887 .^{2}$ That study was followed by a number of very early metallographic investigations of proeutectoid cementite including those by Osmond (1893), ${ }^{3}$ Howe (1911), ${ }^{4}$ Forsman (1918), ${ }^{5}$ Hendricks (1930), ${ }^{6}$ Mehl et al. (1933), ${ }^{7}$ and Greninger and Troiano (1940). ${ }^{8}$ Cementite is a brittle compound phase with the stoichiometry, $\mathrm{M}_{3} \mathrm{C}$, where $\mathrm{M}$ is primarily $\mathrm{Fe}$ but may include other substitutional alloying elements such as $\mathrm{Mn}, \mathrm{Ni}, \mathrm{Cr}$, etc. From a technological perspective, proeutectoid cementite can be undesirable due to its brittle nature, particularly if it forms continuous networks along prior austenite grain boundaries (e.g. see cementite films along austenite grain 


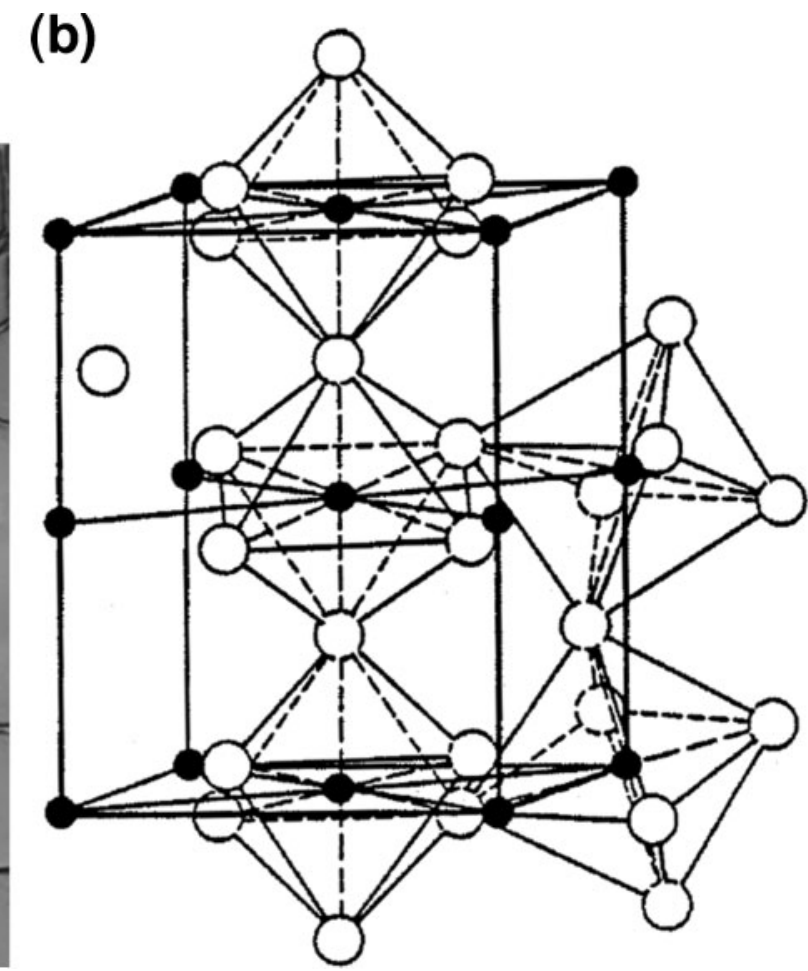

$1 \mathrm{a}$ an optical micrograph of cementite precipitates (arrowed) in austenite matrix in $\mathrm{Fe}-1.3 \mathrm{C}-13 \mathrm{Mn}$ alloy reacted at $650^{\circ} \mathrm{C}$ for $50 \mathrm{~s}$ (taken from Kral et al. ${ }^{16}$ ); $b$ schematic representation of cementite lattice - positions of carbon atoms are represented by filled circles while iron atoms are shown as larger, open circles (taken from Hendricks ${ }^{6}$ )

boundaries in Fig. 1a). Cementite has an orthorhombic crystal structure containing $12 \mathrm{Fe}$ (or $\mathrm{M}$ ) atoms and $4 \mathrm{C}$ atoms per unit cell (Fig. 1b). The term 'proeutectoid' was originally used to refer to cementite formed from the austenite phase above the eutectoid temperature, in the austenite plus cementite two phase field of the $\mathrm{Fe}-\mathrm{C}$ phase diagram. It is now also commonly used to refer to cementite which forms directly from the high temperature austenite phase below the eutectoid temperature in a metastable fashion without accompanying ferrite precipitation (see Fig. 2).

Although a brief overview of proeutectoid cementite was provided in 2001 in 'The Encyclopedia of Materials', a comprehensive review of this 'classic' phase transformation in steels has not been published since 1962, when Professor Hubert I. Aaronson covered the topic (in addition to the proeutectoid ferrite transformation) in a section of the book entitled 'The Decomposition of Austenite by Diffusional Processes'. A number of experimental and computer based techniques have come available since that time, and recent investigations have leveraged these methods to bring about a number of ground breaking new findings about the proeutectoid cementite transformation (particularly in the last decade). It is therefore now quite timely for a new review on this classic phase transformation. A major goal of this review is thus to set the earlier literature in the proper context of more recent findings, and to revise it when necessary, with the aim of providing an entirely new comprehensive picture of the proeutectoid cementite transformation. The present work thus represents an up to date, comprehensive, and detailed review of the proeutectoid cementite transformation.

After presenting a brief description of the temperature-composition range of the formation of proeutectoid cementite in $\mathrm{Fe}-\mathrm{C}$ and alloy steels, this review will cover the following topical areas in considerable detail. The section on 'Proeutectoid cementite morphologies' provides two and three dimensional observations of the morphology of proeutectoid cementite; the next section presents the crystallographic orientation relationships between proeutectoid cementite and the austenite matrix from which it forms; habit planes, growth directions, and cementite/austenite interfacial structure of proeutectoid cementite precipitates will be presented in the next section; then the growth

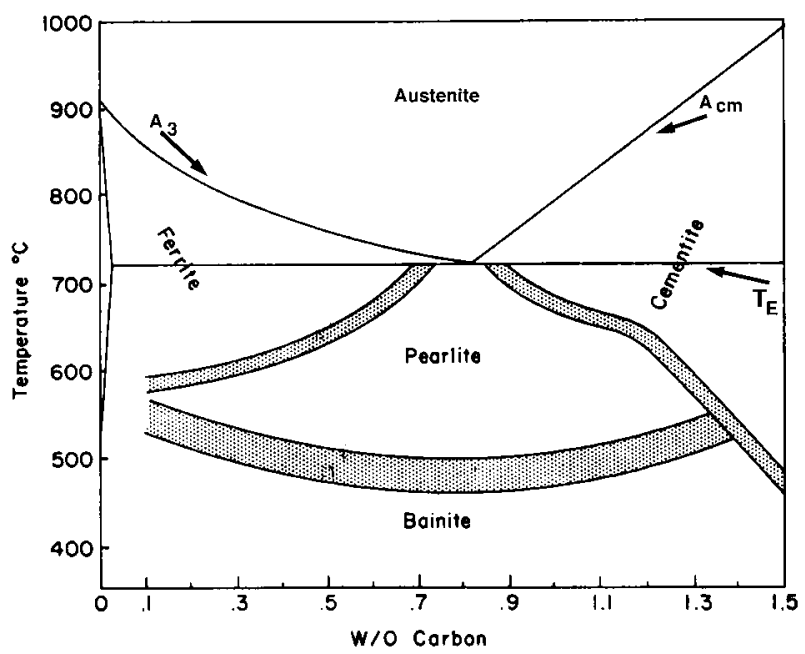

2 Temperature-composition regions in which ferrite, cementite, pearlite, and bainite reactions are dominant in plain carbon steels (taken and slightly modified from Aaronson): ${ }^{1} T_{E}$ is eutectoid temperature, $A_{3}$ is austenite/ austenite + ferrite phase boundary, and $A_{\mathrm{cm}}$ is austenite/ austenite + cementite phase boundary 
kinetics of proeutectoid cementite will be described; the last section is about the formation mechanism(s) of proeutectoid cementite.

More specifically, although there have been a number of detailed early investigations of proeutectoid cementite morphology (e.g. Ref. 7, 8 and 10-12), this review will consider those earlier results in light of a number of newer studies that have provided critical new insight on cementite morphologies, in both two and three dimensions (e.g. see Ref. 13-20). This review will also examine various reports in the literature of a number of different crystallographic orientation relationships (ORs) between proeutectoid cementite and the austenite matrix from which it forms, ${ }^{21-26}$ which in some cases have led to confusion. To add some clarity to this subject, the differences, commonalities, important features, and redundancies of these ORs will be considered in a unified way. The habit plane, growth direction, and interfacial structure (which are all strongly related to the formation mechanism and growth of proeutectoid cementite) will then be evaluated for various morphologies of proeutectoid cementite. These results will be considered in a hierarchical fashion - from the scanning electron microscopy (SEM) level, to the conventional transmission electron microscopy (TEM) level, to the atomic level of resolution, and will be related to both the morphology and the crystallography (ORs) evaluated earlier in the review. Existing modelling studies of the habit plane, growth direction, and interfacial structure of proeutectoid cementite will also be critically reviewed. Quantitative experimental and theoretical investigations of the growth kinetics of the proeutectoid cementite transformation will then be considered. Concerning specific alloy systems, it should be noted that high manganese hypereutectoid steels have been studied extensively in a number of the investigations (particularly the more recent ones) just mentioned. This is because such high Mn alloys are relatively well suited for experimental studies of the morphology, interfacial structure, crystallography, and kinetics of the proeutectoid cementite transformation, in large part because they allow for full retention at room temperature of the austenite matrix phase from which the cementite forms. It has also been convenient that the austenite matrix can be etched away to reveal intact cementite networks in three dimensions.

The last major section of this paper on 'Formation mechanism(s) of proeutectoid cementite' will then sum up, build upon, and integrate the foundation of results discussed in detail in the earlier sections, in order to provide a comprehensive, modern, view of the formation mechanism(s) of proeutectoid cementite. This last section is thus critical in tying together all of the specific findings to form a complete picture of this classic phase transformation. Finally, it should be mentioned that many of the new findings, issues, and features of the proeutectoid cementite transformation presented here provide a model of which many aspects may be more broadly applicable to a number of other phase transformations systems.

\section{Temperature-composition range of formation of proeutectoid cementite}

Proeutectoid cementite typically forms in steels when the carbon content is greater than that of the eutectoid composition (hypereutectoid steels) (see Fig. 2). At equilibrium, proeutectoid cementite forms above the eutectoid temperature $\left(T_{\mathrm{E}}\right)$, but below the $A_{\mathrm{cm}}$ temperature. The $A_{\mathrm{cm}}$ temperature for a specific carbon composition is given by the boundary between the single phase austenite, and the two phase austenite plus cementite phase fields (Fig. 2). Proeutectoid cementite can also form metastably directly from the high temperature austenite phase, below the eutectoid temperature, without accompanying ferrite precipitation (the latter of which occurs during pearlite or bainite formation). For plain carbon steels, i.e. $\mathrm{Fe}-\mathrm{C}$ based alloys containing about $0.5 \% \mathrm{Mn}$ and $0.25 \% \mathrm{Si}$ (all alloy percentages presented in this paper will be in wt- $\%)$, the eutectoid composition corresponds to a carbon composition of about $0.8 \%$, and the eutectoid temperature is approximately $725^{\circ} \mathrm{C}$. $^{27}$

Significant amounts of alloying elements can dramatically change the eutectoid composition, as well as the $T_{\mathrm{E}}$ and $A_{\mathrm{cm}}$ temperatures, and can also change the number of phases present in the phase fields on the phase diagram. For instance, in ternary systems, according to the Gibbs phase rule, three phases can exist simultaneously in certain regions of the relevant phase diagrams. Reference 27 provides a number of pseudo binary phase diagrams with effective eutectoid compositions and temperatures for various ternary and quaternary alloy steels. A review of the effects of alloying elements on the $\mathrm{Fe}-\mathrm{C}$ phase diagram is out of the scope of the present paper, and there are many reports in the literature on this subject (e.g. see Ref 2729). Software packages and databases which can be used to calculate such phase diagrams are also now readily available. $^{30,31}$ It is also worth mentioning that it has been shown recently that the presence of a strong magnetic field can shift the eutectoid point to higher carbon compositions and higher temperatures, thus reducing the driving force for the composition-temperature range of the proeutectoid cementite transformation. ${ }^{32}$

\section{Proeutectoid cementite morphologies}

It will be helpful at the outset of this section to distinguish between the different types of two-dimensional (2D) and three-dimensional (3D) morphological observations that will be considered. These distinctions will often be based here primarily on the type of characterisation technique employed. Two-dimensional observations will include those made with:

(i) conventional optical microscopy on single planes of polish

(ii) conventional scanning electron microscopy (SEM) on single planes of polish

(iii) conventional thin foil transmission electron microscopy (TEM) in which the image is formed from a projection through a very thin slice ( $\sim 100 \mathrm{~nm}$ or less) of material.

Three-dimensional observations will refer to observations based on techniques including:

(i) optical microscopy plus serial sectioning and computer aided three-dimensional reconstruction

(ii) optical microscopy in conjunction with deep etching

(iii) SEM in conjunction with deep etching 
(a)

(b)
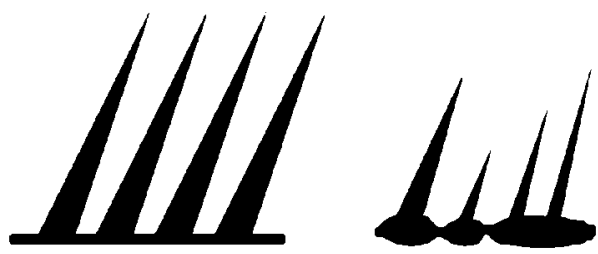

(c)

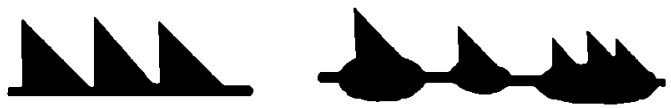

(d)
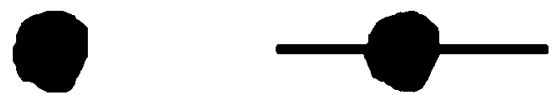

(e)

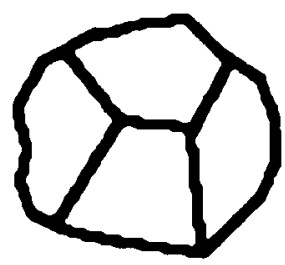

a grain boundary allotriomorphs; $b$ primary and secondary Widmanstätten sideplates; $c$ primary and secondary Widmanstätten sawteeth; $d$ idiomorphs; e intragranular Widmanstätten plates (or needles); $f$ massive structures

3 Dubé morphological classification system, ${ }^{33,34}$ as modified by Aaronson ${ }^{1}$

(iv) a relatively new technique ${ }^{19}$ combining deep etching and thin foil TEM.

Dubé developed his 2D morphological classification system for proeutectoid ferrite in the early $1950 \mathrm{~s},{ }^{33,34}$ and it is still widely used today. Later the system was applied by Aaronson to proeutectoid cementite as well (see Fig. 3). ${ }^{1}$ This classification of precipitate shapes was based solely on 2D observations from single planes of polish (albeit very many separate 2D observations), and has been briefly reviewed more recently. ${ }^{16}$ The morphologies in this classification system ${ }^{1,33,34}$ include grain boundary 'allotriomorphs' which are found at matrix phase grain boundaries and are often described as 'bulged pancakes" ${ }^{\prime}$ or two abutting spherical caps (see Fig. 3a). Widmanstätten sideplates or needles (Fig. 3b) extend into the matrix grains after nucleating directly on the matrix grain boundaries (primary sideplates) or upon allotriomorphic precipitates already nucleated at the grain boundaries (secondary sideplates). Primary and secondary Widmanstätten sawteeth are similar to sideplates, but have a larger angle of incidence with the grain boundary, at least based on 2D observations (see Fig. $3 c$ ). Idiomorphs (Fig. $3 d$ ) are equiaxed crystals that usually form inside of matrix grains, but sometimes are observed on grain boundaries. Intragranular Widmanstätten plates or needles lie wholly within austenite grains (Fig. 3e), and 'massive structures' are aggregates of impinged precipitate crystals inside the matrix grains (see Fig. 3f). It has been shown more
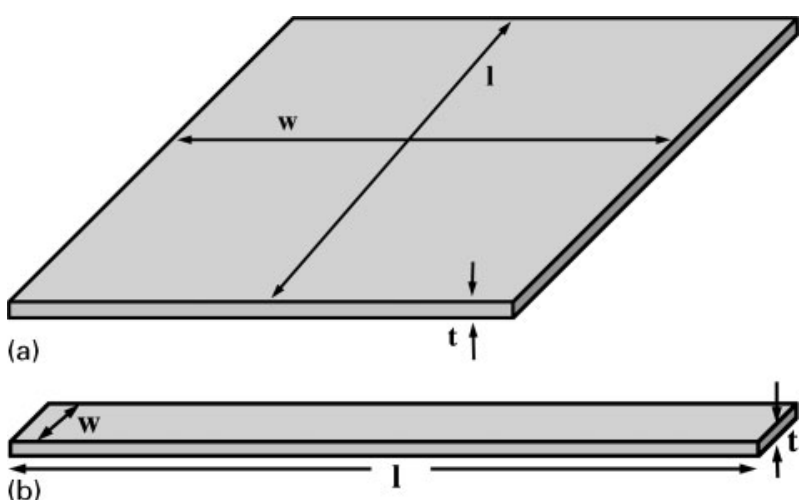

4 Schematic representations of idealised 3D a plate and $b$ lath morphologies, where $t=$ thickness, $w=$ width and $I=$ length: note that plate in $a$ has been idealised to have square broad face in which $I=w$

recently ${ }^{16,35,36}$ that $3 \mathrm{D}$ analysis is required to accurately characterise these complex morphologies, such that newer work has led to a revision of the Dubé morphological classification system for proeutectoid ferrite $^{35,36}$ and proeutectoid cementite morphologies, ${ }^{13,16}$ the latter of which will be described in detail below.

\section{Widmanstätten cementite morphologies}

Before considering the detailed observations of proeutectoid cementite morphology, it is worthwhile to define what is meant by the term 'Widmanstätten'. This term originated from the observation of certain figures appearing on etched specimens taken from iron based meteorites, and was thus named after A. B. Widmanstätten, of Vienna, Austria, who first described such observations on meteorites in $1808 .{ }^{37,38}$ The metallurgical community subsequently adopted this terminology (e.g. see Ref. 7, 39 and 40) to describe phases with elongated shapes as possessing a Widmanstätten morphology. It is also important here to distinguish clearly between the 'plate' and 'lath' variations of the Widmanstätten morphology (see Fig. 4). Both shapes have a very thin dimension represented by the thickness $(t)$, while a plate has both its length $(l)$ and its width $(w)$ being of similar dimensions (Fig. 4a). A lath on the other hand is such that its length $(l)$ is significantly greater than its width (w) (see Fig. 4b)

In 1933, Mehl et al. ${ }^{7}$ stated that in hypereutectoid steels 'Widmanstätten cementite is correctly understood as plate like in outward form'. This strong statement and related discussions in that paper may have contributed to leading subsequent researchers somewhat astray. As will be discussed in considerable detail below, it was not plainly shown until much later ${ }^{13,16,17}$ that Widmanstätten cementite is actually either plate like or lath like in three dimensions. In the long gap between Mehl et al. ${ }^{7}$ and the work of Kral et al. ${ }^{13,16,17}$ there were many more reports of plate like shapes, but little specific evidence was reported on what are now known as Widmanstätten laths, until the work of Khalid et al. ${ }^{41}$ Even then, it was not understood until later ${ }^{17}$ that these two Widmanstätten variations are completely different in both morphology, and crystallographic orientation relationship. In the following section, consideration will first be given to experimental observations of what were termed proeutectoid cementite 'plates', based on 2D 
characterisation by optical microscopy, SEM, and/or thin foil TEM. It is critical to understand that the progress in understanding the true morphology of proeutectoid cementite was dependent upon 3D observations combined with crystallography, and that much of the confusion that existed in the literature was due to the difficulty in making general descriptions from $2 \mathrm{D}$ observations alone. Thus, the following subsections are divided into 'early' observations, based predominantly on $2 \mathrm{D}$ methods of characterisation, and those that were made as a result of $3 \mathrm{D}$ analyses.

\section{'Early' observations of proeutectoid Widmanstätten cementite 'plates'}

In 1933, Mehl et al. employed extremely careful, detailed experimental methods combining optical microscopy and X-ray diffraction of single austenite grains, to study the morphology and crystallography of proeutectoid cementite. ${ }^{7}$ Pseudo 3D observations of large single austenite crystals were made by sectioning and polishing samples on three orthogonal planes. As mentioned above, their observations indicated that Widmanstätten cementite adopted a plate like form. A complicated structure was revealed at higher magnifications, including observations of surface corrugations, laminations, and serrations, and these were attributed at least in part to the volume change during the transformation. Greninger and Troiano subsequently (1940) made similar observations to Mehl et. al. of proeutectoid cementite precipitates which they also suggested possessed a plate morphology. ${ }^{8}$ Heckel and Paxton later employed 2D optical microscopy techniques to study the morphology, ${ }^{11}$ growth, ${ }^{42}$ and habit plane ${ }^{43}$ of proeutectoid cementite precipitates, and one of the microconstituents they investigated was referred to as Widmanstätten plates. Heckel and Paxton also set their observed proeutectoid cementite morphologies in the context of the Dube classification system, ${ }^{33,34}$ and reported on observations of both Widmanstätten sideplates (Fig. 3b) and intragranular Widmanstätten plates (Fig. 3e). ${ }^{11}$ Aaronson ${ }^{1}$ predominantly used the observations of Heckel et al. ${ }^{11,42,43}$ as a basis for his extension of the Dube classification system to proeutectoid cementite, as mentioned above and depicted in Fig. 3. He thus reported on cementite sideplates, intragranular plates, and 'degenerate' plates. Degenerate cementite plates were described as sometimes possessing a 'wavy' shape, but more often having a morphology which suggested that they were actually formed by the sympathetic nucleation $^{4446}$ of a number of smaller cementite crystals. ${ }^{1}$ Sympathetic nucleation has been defined as the nucleation of a precipitate crystal at an interphase boundary of a crystal of the same phase when these two crystals differ in composition from their matrix phase throughout the transformation process. ${ }^{44} 46$

In a later crystallographic study of austenitecementite orientation relationships, Thompson and Howe $^{47,48}$ referred to the precipitates that they observed by thin foil TEM as intragranularly nucleated cementite plates. At about the same time, Spanos and Aaronson made a number of observations of the morphology, formation mechanism and crystallography of what they termed proeutectoid cementite plates, based on conventional thin foil TEM (2D) analyses in high $\mathrm{Mn}$ hypereutectoid steels. ${ }^{12,49}$ The latter results included the suggestion and more detailed analysis of sympathetic nucleation ${ }^{44,46}$ of multiple plates on top of one another, both in face to face and edge to edge arrangements. ${ }^{12}$ In five hypereutectoid high Mn steels containing from $0 \cdot 82-1 \cdot 13 \% \mathrm{C}$, and $9 \cdot 7-13 \cdot 0 \% \mathrm{Mn}$, Khalid et $a l^{41}$ subsequently observed by optical microscopy, TEM and limited deep etching SEM techniques long thin plates with further evidence of what they termed smaller plate segments (the latter observation was based predominantly on 2D optical microscopy). These 'smaller segments' will be further examined below based on 3D analyses. Additionally, 'rectilinear plates' with a 'pronounced layered structure', as observed by optical microscopy, were reported by Bataev et al. in a $1 \cdot 3 \% \mathrm{C}$ steel. $^{50}$

Many of the different early conclusions on cementite 'plates' which were based predominantly on 2D observations will be elucidated and re-evaluated in the section below based on $3 \mathrm{D}$ observations.

\section{Three-dimensional observations of proeutectoid Widmanstätten cementite plates}

In about the mid 1990s, computer software and hardware had advanced enough to make the computer aided reconstruction and visualisation of serial section data from metals viable. ${ }^{51,52}$ Mangan, Lauren and Shiflet were the first to apply these techniques to proeutectoid cementite when they reconstructed four Widmanstätten cementite precipitates in a $12 \cdot 3 \mathrm{Mn}-0 \cdot 8 \mathrm{C}$ steel, and also determined their crystallographic orientation relationship with austenite by electron backscatter diffraction (EBSD) analysis. ${ }^{14}$ An interesting intersection between these Widmanstätten crystals was revealed, in which one crystal apparently grew through another. The EBSD analysis proved that this was not just a bifurcation, since the intersecting crystals had completely different crystallographic orientations from one another. These precipitates were described as 'plates' in $3 \mathrm{D}$, due to their having one relatively thin dimension and two relatively long dimension(s) ${ }^{14}$ (i.e. a length to width aspect ratio $\approx 1$, and length/width to thickness aspect ratio $\gg 1$, see Fig. $4 a$ ). Kral and Spanos ${ }^{16}$ subsequently performed serial sectioning and $3 \mathrm{D}$ reconstruction of Widmanstätten cementite crystals in an $\mathrm{Fe}-$ $1 \cdot 34 \mathrm{C}-13 \mathrm{Mn}$ alloy. A volume containing more than 200 entire Widmanstätten precipitates and more than 25 entire austenite grains in which these precipitates were formed was reconstructed. A major goal of that study was to reconstruct entire precipitates and measure their length, width and thickness in $3 \mathrm{D}$, in order to determine their true 3D shape and also to reconstruct the entire austenite grains in which these precipitates grew, to determine unambiguously whether they nucleated intragranularly or intergranularly. In combination with SEM and TEM observations of deep etched specimens, ${ }^{13,16}$ it was shown that there are actually two different 3D morphological categories of Widmanstätten cementite precipitates:

(i) the plates that were mentioned earlier

(ii) laths with the length dimension $\gg$ width $>$ thickness.

The plates were often single crystals (monolithic) but sometimes stacked in a face to face arrangement, while the laths were often conglomerates of many finer laths arranged in an edge to edge fashion. Measurements of precipitate thickness in 3D also suggested that there might be some barrier to the thickening of cementite 


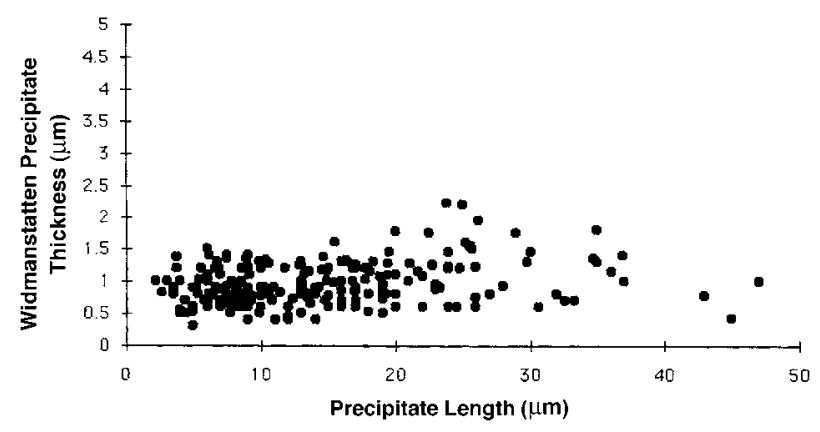

5 Widmanstatten precipitate thickness versus length measured from 3D reconstructions of Widmanstatten cementite precipitates in $\mathrm{Fe}-1.3 \mathrm{C}-13 \mathrm{Mn}$ steel isothermally reacted for $50 \mathrm{~s}$ and $650^{\circ} \mathrm{C}$ (taken from Kral et al. $)^{16}$

plates, because it was shown that thickness remained relatively constant despite large variations in the lengths of the cementite precipitates measured (see Fig. 5). In other words, those Widmanstätten precipitates that had lengthened considerably would have been expected to be thicker as well, since they presumably had grown for longer times, but that was not what was observed. Some of the most important morphological conclusions of that work $^{13,16}$ were thus that

(i) all Widmanstätten cementite precipitates were connected to grain boundary cementite, i.e. there was no evidence of intragranular nucleation

(ii) two different types of Widmanstätten precipitate morphologies (plates and laths) were formed

(iii) there was a barrier to the thickening of Widmanstätten cementite precipitates.

Owing to the significant difference in etching properties of austenite and cementite, when hypereutectoid steels rich in alloying elements are heat treated in such a way so as to fully (or nearly fully) retain the austenite matrix at room temperature, etching away the austenite matrix around the cementite precipitates (deep etching) can be an effective way of revealing three-dimensional characteristics of cementite. ${ }^{7,13,16,41,53}$ Some relatively early investigations thus also used deep etching in conjunction with optical microscopy and/or SEM as a supplementary technique in characterising the morphology of Widmanstätten proeutectoid cementite 'plates'.,41,53 Mehl et al. used deep etching in conjunction with optical microscopy as a complementary technique to suggest that what appeared in standard 2D optical microscopy to be single plates were often 'laminated' in a plane often nearly parallel to the broad faces of the plates. ${ }^{7}$ This 'laminated' morphology likely corresponds to the morphological findings years later by both optical microscopy and transmission electron microscopy, which was attributed to sympathetic nucleation of multiple cementite plates in a face to face arrangement. ${ }^{12}$ Khalid et al. ${ }^{41}$ subsequently showed an example of a deep etched specimen and from it suggested that the "long thin plates evident in the light microscope can be composed of smaller planar segments'. They also mentioned that 'this provides further support to earlier suggestions ${ }^{12,53}$ that cementite laths may be composed of individual subunits', and that these observations 'reinforced evidence of sympathetic nucleation of groups of plates'. ${ }^{41}$

Other investigators later performed exhaustive deep etching studies in an $\mathrm{Fe}-1 \cdot 34 \mathrm{C}-13 \mathrm{Mn}$ alloy, ${ }^{13,16,17}$ including sequential deep etching and characterisation from individual areas, ${ }^{13}$ in order to make a number of observations on the 3D morphology of Widmanstätten cementite. As in previous studies, cementite plates were indeed observed in 3D by SEM studies of deep etched samples, ${ }^{13,16,17}$ which corroborated the observations made by serial sectioning in conjunction with the optical microscopy and computerised $3 \mathrm{D}$ reconstruction ${ }^{16}$ of precipitates with a length/width $(l / w)$ aspect ratio of nearly 1 (corresponding to plates in three dimensions). Based on further deep etching SEM observations, it was pointed out that in $3 \mathrm{D}$ these cementite plates sometimes appeared to be stacked atop one another in a face to face fashion (see Fig. 6a), reinforcing the earlier reports that they may be composed of multiple, sympathetically nucleated crystals. ${ }^{12,41}$ Another somewhat striking observation was that these plates occasionally had many cementite laths intersecting them, in a fashion in which the plates appeared to have continued to grow around the laths as they evolved ${ }^{13}$ (see Fig. 6d). This could correspond to the intersections that Mangan et al. observed in their 3D serial sectioning studies. ${ }^{14}$ Mangan et al. referred to the four Widmanstätten crystals they observed as plates; however, it might be possible that one or more were laths rather than plates, since they were apparently truncated by the edges of the reconstruction volume. Alternatively, it cannot be unequivocally ruled out that those observations ${ }^{14}$ did indeed correspond to intersections of multiple plates, while the other study ${ }^{13}$ documented many cases of laths intersecting plates.

It was also found that if specimens are heat treated in a way such that a continuous network of grain boundary and Widmanstätten cementite develops, TEM foils can then be deep etched so that the austenite matrix all dissolves away, yet the interconnected cementite network remains intact in the TEM foils, and the cementite structures are thin enough that they are transparent to electrons. ${ }^{19}$ This technique ${ }^{19}$ proved to be quite valuable in that it allowed for simultaneous observation at the TEM level of resolution of

(i) the 3D morphology and interconnectivity of the cementite crystals

(ii) smaller aggregates of very fine crystals composing what appeared to be monolithic crystals when observed by lower resolution 3D techniques (optical microscopy or SEM)

(iii) the detailed crystallographic orientation of individual cementite crystals relative to one another, by employing both selected area diffraction (SAD) and convergent beam electron diffraction (CBED)

(iv) the structure of cementite/cementite grain boundaries between the $3 \mathrm{D}$ cementite crystals in contact with one another. ${ }^{16,17,19,20}$

These studies revealed a particularly important observation about the internal morphology of cementite plates in 3D: what appeared to be monolithic cementite plate shaped crystals by optical microscopy in conjunction with serial sectioning and $3 \mathrm{D}$ reconstruction, ${ }^{16}$ were actually composed of monolithic single crystals with a 3D plate morphology at this fine level of resolution as well, but were occasionally stacked atop one another in a fashion typical of the face to face morphology of sympathetic nucleation ${ }^{12}$ (see Fig. $6 a$ and $c$ ). TEM 

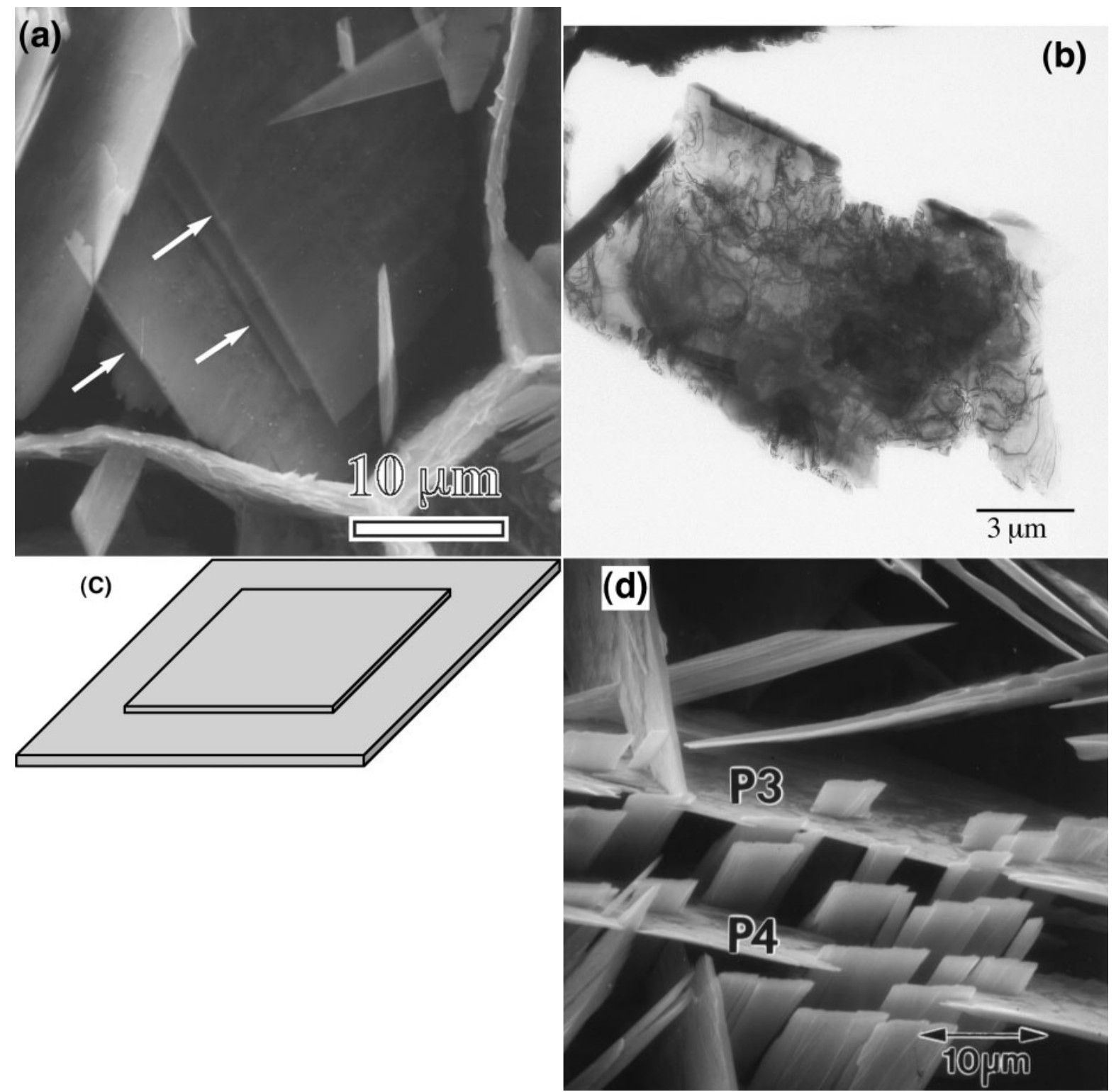

a micrograph (SEM) of deeply etched specimen, in which austenite was completely etched away, showing three monolithic cementite plates (arrowed) sitting atop one another in face to face arrangement (taken from Mangan et al. ${ }^{17}$ ); $b$ micrograph (TEM) of deeply etched specimen showing cementite plate which was shown by convergent beam electron diffraction (CBED) and imaging under various tilt conditions to be monolithic single crystal: changes in contrast are due to discrete changes in thickness of plate, in addition to what appear to be some bend contours (taken from Kral et al. ${ }^{16}$ ); $c$ idealised schematic of two cementite plates stacked in face to face arrangement; $d$ micrograph (SEM) showing laths intersecting plates (P3, P4) which appear to have grown around laths (taken from Kral et al. ${ }^{13}$ )

6 Micrographs and idealised schematic representation demonstrating 3D morphology of Widmanstatten cementite plates: all micrographs were taken from $\mathrm{Fe}-1 \cdot 3 \mathrm{C}-13 \mathrm{Mn}$ alloy, with micrographs in $a$ and $b$ corresponding to specimens isothermally reacted at $650^{\circ} \mathrm{C}$ for $50 \mathrm{~s}$, while $d$ is for specimen isothermally reacted at $650^{\circ} \mathrm{C}$ for $700 \mathrm{~s}$

selected area diffraction, convergent beam electron diffraction, and dark field analyses indicated that the monolithic plates stacked in this face to face arrangement had no, or very little, misorientation between them. ${ }^{16,17}$ As will be seen below, these results were in striking contrast to observations on cementite lath morphologies, using the same 3D observation techniques.

All of the 3D observations taken together thus permit a much more complete and modern picture of the true 'plate' variant of morphology of Widmanstätten proeutectoid cementite - as shown schematically in Fig. $6 c$. The picture that has evolved is one of an internal morphology of individual monolithic cementite crystals which do indeed have a plate morphology in three dimensions (i.e. a width/length ratio $\approx 1$, see Fig. $4 a$ ) even at fine levels of resolution, rather than being composed of many finer crystals sympathetically nucleated in an edge to edge fashion, as was suggested earlier as one of the mechanisms of the evolution of cementite 'plates', based on 2D observations alone. ${ }^{12}$ On the other hand, these true $3 \mathrm{D}$ plates can and do sometimes stack in a face to face arrangement of sympathetic nucleation (Fig. 6c) having little or no misorientation between the individuals plates. ${ }^{16,17}$ This face to face morphological arrangement was also suggested in the earlier 2D study. ${ }^{12}$ This 3D morphology has additionally been corroborated by deep etching in conjunction with $\mathrm{SEM}^{16}$ (see Fig. 6a), and as mentioned above, likely 
corresponds to the 'laminations' reported much earlier by Mehl et. al. ${ }^{7}$ using deep etching in conjunction with optical microscopy. Although these newer observations may also contribute to the description of 'degenerate plates' by Aaronson, ${ }^{1}$ observations of degenerate cementite plates, as well as the deductions of edge to edge sympathetic nucleation of Widmanstätten cementite, ${ }^{12}$ may be better explained as related to lath morphologies, as will be discussed below.

\section{'Early' observations of proeutectoid Widmanstätten cementite 'laths'}

Based on 2D observations by optical microscopy, SEM, and/or thin foil TEM, almost no researchers characterised Widmanstätten cementite as laths. Instead, when based on 2D observations alone, the majority of studies have referred to Widmanstätten cementite crystals exclusively as 'plates'. 1,7,11,12,14,15,18,21,23,25,41-43,47-50,54-58 Nevertheless, the few reports of cementite laths in investigations utilising predominantly $2 \mathrm{D}$ techniques will now be reviewed.

In a thin foil TEM study in a carburised 9310 steel in which the carbon level in the carburised layer was as high as $1.65 \mathrm{wt}-\%$, the Widmanstätten cementite observed was referred to as predominantly rods, but the terminology 'rods (or laths)' was also used. ${ }^{59}$ It was suggested that the internal structure of what appeared to be plates by optical microscopy actually consisted of an agglomeration of numerous fine rods or laths (e.g. see Figs. 3, 6 and 7 of Ref. 59). Based on the discussion above, this is in stark contrast to 'plates' observed at the optical microscopy level by other researchers, which were clearly shown by high resolution $3 \mathrm{D}$ techniques (TEM and SEM in conjunction with deep etching) to be single, monolithic plates in three dimensions that were occasionally stacked in a face to face arrangement. ${ }^{16,17}$ On the other hand, these findings ${ }^{59}$ could be related to the deductions in the one 2D study mentioned above, ${ }^{12}$ in which it was suggested that what were thought of at that time to be plates were composed of many finer crystals sympathetically nucleated in an edge to edge fashion. ${ }^{12}$

In a study of a $0 \cdot 8 \mathrm{C}-12 \mathrm{Mn}$ steel, Cowley and Edmonds reported observations of intragranular cementite laths, in addition to intergranularly nucleated proeutectoid cementite sideplates. ${ }^{53}$ Although this study employed predominantly thin foil TEM techniques, the TEM observations were correlated with the SEM observations of a deep etched specimen (see Fig. 2 of Ref. 53), the latter of which will be discussed in more detail below. Based on the 2D TEM observations they described 'sheaves of laths' which were also suggested to have formed by sympathetic nucleation; the authors did not elaborate further on the external morphology of these sheaves. ${ }^{53}$ These observations are similar to those reported that same year by other researchers, ${ }^{12}$ in which Widmanstätten proeutectoid cementite that was suggested to have an external plate morphology was deduced to have formed by both face to face and edge to edge sympathetic nucleation of finer cementite crystals. The latter study, on the other hand, did not explicitly elaborate on the internal morphology, i.e. the shape of the individual fine crystals making up proeutectoid cementite that was assumed to possess a plate like external morphology at the 2D optical microscopy level of resolution. ${ }^{12}$ The findings of Cowley and

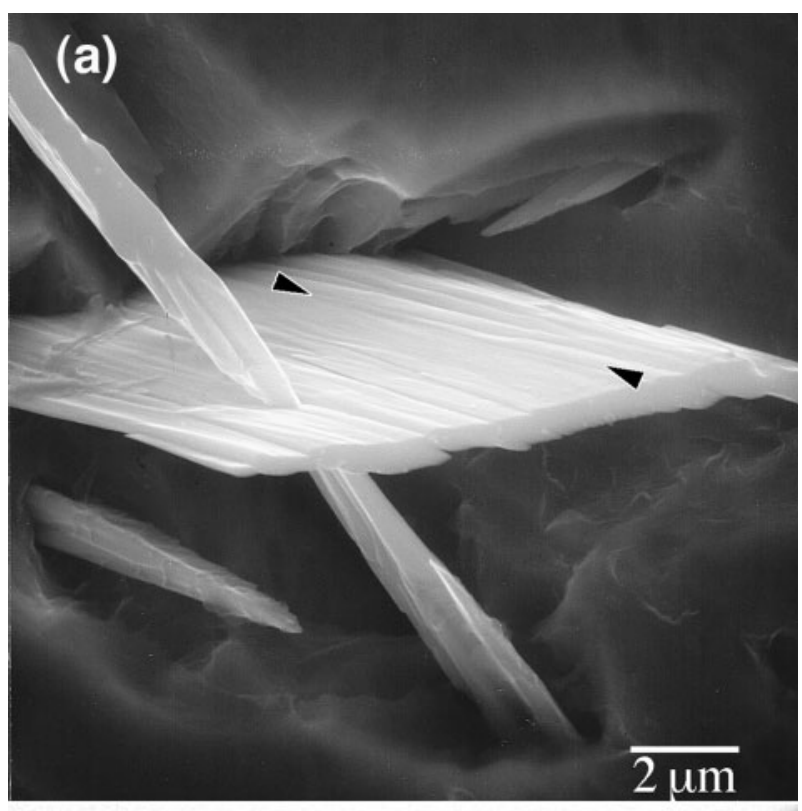

(b)

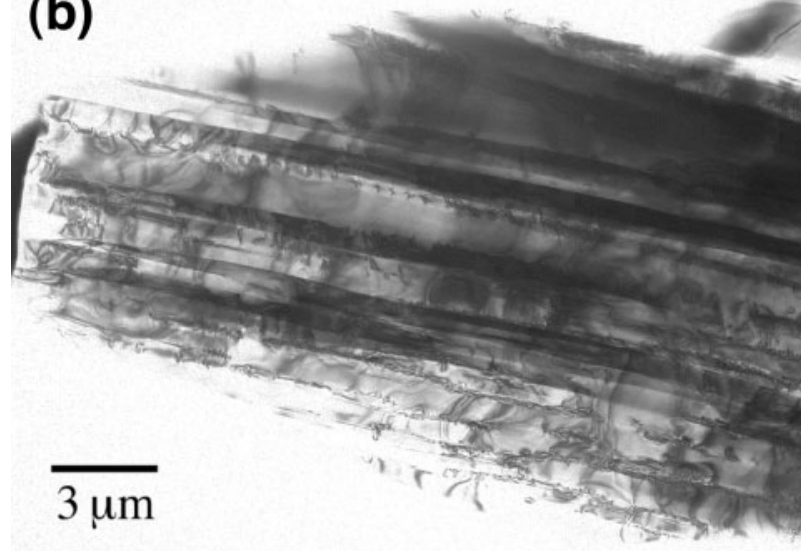

(c)

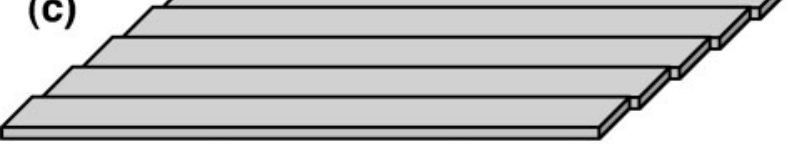

a micrograph (SEM) of deeply etched specimen in which austenite was completely etched away, showing striations (e.g. see arrows) exhibited by conglomerate of cementite laths (taken from Mangan et al. ${ }^{17}$ ); $b$ micrograph (TEM) of deeply etched specimen showing that Widmanstatten cementite with external lath morphology is composed of fine lath shaped subunits, shown by convergent beam electron diffraction (CBED) to have small misorientations between fine laths (taken from Kral et al. ${ }^{16}$ ); $c$ idealised schematic of multiple fine lath shaped subunits stacked in edge to edge arrangement, forming overall conglomerate of laths

7 Micrographs and idealised schematic representation demonstrating 3D morphology of Widmanstatten cementite laths: both micrographs were taken from $\mathrm{Fe}-$ $1 \cdot 3 \mathrm{C}-13 \mathrm{Mn}$ alloy isothermally reacted at $650 \mathrm{C}$ for $50 \mathrm{~s}$

Edmonds ${ }^{53}$ might additionally be related to the earlier reports of 'laminated plates', ${ }^{7}$ as well as to observations by Krasnowski and Hruska, who reported that the internal structure of what appeared to be individual plates by optical microscopy actually consisted of an agglomeration of numerous fine rods or laths. ${ }^{59}$ Some of the apparent differences and common features of these

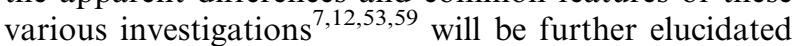
now based on consideration of newer 3D observations. 


\section{Three-dimensional observations of proeutectoid Widmanstätten cementite laths}

More recently, a variety of techniques was employed to provide direct 3D observations of Widmanstätten proeutectoid cementite precipitates that were shown to possess a true lath morphology in three dimensions. As referred to earlier in the discussion of cementite plates, in an investigation which employed serial sectioning in conjunction with optical microscopy and computerised $3 \mathrm{D}$ reconstructions of the serial section images, morphologies were quantified by measurement in three dimensions of the thickness $(t)$, width $(w)$, and length $(l)$ of Widmanstätten cementite precipitates. At that level of resolution (about $0.2 \mu \mathrm{m}$, as dictated by the sectioning depth employed), it was shown that the external morphology of Widmanstätten proeutectoid cementite possessed both lath $(l / w \sim \geqslant 5)$ and plate $(l / w \sim 1)$ morphologies, and 'hybrid' shapes between an external morphology corresponding to a plate or a lath $(1<$ $l / w<5)$ were also observed. ${ }^{16,60}$ It is emphasised here that due to the limited resolution of this technique, those observations should be restricted to consideration of the external morphology of Widmanstätten cementite only. Details of the finer internal morphology will now be considered in studies that employed higher resolution 3D techniques.

As also mentioned above, Cowley and Edmonds ${ }^{53}$ used deep etching in conjunction with SEM as a complementary technique to their predominantly TEM study of Widmanstätten cementite in a $0 \cdot 8 \mathrm{C}-12 \mathrm{Mn}$ steel, and showed an SEM micrograph of a deeply etched specimen which strongly suggested the presence of Widmanstätten cementite precipitates that possessed an external lath morphology. The subsequent deep etching studies in an $\mathrm{Fe}-1 \cdot 34 \mathrm{C}-13 \mathrm{Mn}$ alloy by other researchers, whose findings on cementite plate morphologies were considered earlier in this review, also contained a number of important observations of both the external and internal morphology of cementite laths. ${ }^{13,16,17}$ These observations are especially important in light of the fact that before these studies, the great majority of investigations considered proeutectoid Widmanstätten cementite to possess a plate morphology. $1,7,11,12,14,15,18,21,23,25,41-43,47-50,54-58$ These deep etching SEM studies ${ }^{13,16,17}$ corroborated the observations made by serial sectioning in conjunction with optical microscopy and computerised $3 \mathrm{D}$ reconstruction ${ }^{16}$ that in addition to the observed plate morphologies, a considerable number of Widmanstätten cementite precipitates possessed an external morphology corresponding to laths in three dimensions (i.e. roughly, $l / w>5$, see Fig. 4b). Based on these deep etching SEM observations, it was pointed out that cementite precipitates which possessed an external (i.e. lower resolution) lath shape, often had many large striations on their broad faces, as shown in Fig. 7a. This led to the deduction that these laths also might be composed of multiple, finer and sympathetically nucleated crystals, as was suggested by earlier researchers for cementite plates. ${ }^{12,41}$

Utilising the deep etching TEM technique mentioned previously, ${ }^{19}$ a number of other important observations of cementite laths were also made. ${ }^{16,17,19,20}$ First, for microconstituents that appeared by serial sectioning and $3 \mathrm{D}$ reconstruction at the optical level of resolution (i.e. the external morphology) ${ }^{16}$ to be either (i) single, monolithic cementite laths $(1 / \mathrm{w} \sim>5)$, or (ii) single, monolithic precipitates possessing a 'hybrid morphology' between that of ideal laths or plates (e.g. $l / w$ ratios less than 5 but significantly greater than 1), it was shown that both of these external morphologies possessed a more complex internal morphology. These entities were actually composed of a very large number of very fine lath 'subunits' in $3 \mathrm{D}$, each approximately $0.25 \mu \mathrm{m}$ in width, arranged in an edge to edge fashion, and separated by distinct cementite/cementite boundaries ${ }^{16}$ (see Fig. 7b). Convergent beam electron diffraction from the fine lath subunits in these deep etched TEM specimens indicated that these individual cementite crystals possessed discrete and small misorientations of typically $2^{\circ}$ or less between adjacent crystals. An additional observation was that occasionally the fine, lath shaped subunits had no apparent connection to any feature other than their adjacent subunits, indicating that they formed by sympathetic nucleation, rather than impingement. ${ }^{16}$

All of the relevant $3 \mathrm{D}^{16,17,19,20,53}$ and $2 \mathrm{D}^{53,59}$ observations taken together thus allow for a much more complete picture of the 'lath' variant of Widmanstätten proeutectoid morphology, as shown schematically in Fig. $7 c$. The picture that has now evolved is one of an internal morphology of many individual fine laths of cementite, on the order of $0.25 \mu \mathrm{m}$ in width in $3 \mathrm{D}$, which form as conglomerates whose external 3D morphology, as viewed by $3 \mathrm{D}$ reconstruction at the optical level of resolution, is typically that of laths (or 'lath hybrids' - wide laths approaching an aspect ratio corresponding to that of plates). Since they were viewed on 2D planes of polish, these lath aggregates were probably mistaken as plates by many researchers in the past. $1,7,11,12,14,15,18,21,23,25,41-43,47-50,54-58$ Additional evidence supporting this deduction is that in some of the detailed $3 \mathrm{D}$ studies, a number of the precipitates that appeared to be plates in individual 2D cross-sections (and typically would have been classified as such based on their 2D appearance), were shown to be aggregates of fine laths when fully reconstructed in $3 \mathrm{D} .^{16,17,19,20}$ Similar correlations have been made from the results of sequential deep etching experiments. ${ }^{16,17,19,20}$

Further to this line of reasoning, it is interesting to point out that, even though micrographs from earlier studies show shapes which with the benefit of the knowledge from the newer investigations can now clearly be deduced to correspond to a morphology other than that of plates, researchers concentrated solely on the plate like morphologies, or perhaps assumed that plates were the only morphological variant of Widmanstätten cementite. Some particular cases documented in the literature of what now appear to be lath (or lath like) shapes but were explained then as plates or idiomorphs include the serrations and corrugations of plates described by Mehl et al. ${ }^{7}$ Precipitates shown in Fig. $3 G, 9 B$ and $10 D$ in Ref. 11 are also lath like, as are many of the precipitates in Fig. 3 in Ref 18. In Mangan, Lauren, and Shiflet's seminal work, ${ }^{14}$ precipitate \#1 in Fig. 2 was assumed to have a plate shape, while in retrospect this might also be a lath.

\section{Morphology of grain boundary 'allotriomorphs'}

Another major morphology of proeutectoid cementite reported in the literature is that of grain boundary cementite allotriomorphs (depicted schematically in two 
dimensions in Fig. 3a). Observations of grain boundary cementite allotriomorphs based on 2D characterisation by optical microscopy, SEM and/or thin foil TEM will be considered first.

As reported by Aaronson in his 1962 article on the proeutectoid ferrite and proeutectoid cementite reactions, ${ }^{1}$ Sorby first observed networks of ferrite and cementite allotriomorphs during his early metallographic studies in $1887 .^{2}$ Osmond $(1893)^{3}$ and Howe $(1911)^{4}$ later reported that these networks are formed by precipitation of the proeutectoid phase at the austenite grain boundaries. ${ }^{1}$ Heckel and Paxton ${ }^{11}$ reported on observations of proeutectoid cementite in which 'continuous films completely outlining the prior austenite grain boundaries at all except precipitate temperatures close to the $A_{\mathrm{cm}}$...' were observed. Aaronson ${ }^{1}$ subsequently made parallels between the observations of Heckel and Paxton on grain boundary cementite, ${ }^{11,42}$ other researchers on grain boundary ferrite in steels (e.g. Ref. 1), and grain boundary precipitates in many other alloy systems (e.g. Ref. 40, 61 and 62). It was suggested that the grain boundary cementite films corresponded to the latter stages of impingement of individually nucleated cementite allotriomorphs, and based on 2D observations, that ferrite and cementite allotriomorphs at early stages possessed a morphology corresponding to 'pancakes with slightly bulged centres', but that 'appreciable departures from this shape are, however, not infrequent'. ${ }^{1}$ In other words, such precipitates also often met the grain boundary at a relatively large angle of taper, corresponding to shapes that were later approximated as a double spherical caps or oblate ellipsoids. ${ }^{63,64}$ Aaronson summarised this grain boundary allotriomorph morphology in terms of the Dube morphological classification system ${ }^{1,33,34}$ (see Fig. $3 a$ ). Both Aaronson ${ }^{1}$ and Heckel and Paxton ${ }^{11}$ observed that the allotriomorphic morphology predominates at higher temperatures, and defined the Widmanstätten start temperature as the temperature below which Widmanstätten cementite first begins to appear, and above which allotriomorphs predominate. 1,11

Ando and Krauss subsequently used SEM and TEM in conjunction with optical microscopy to study the growth of proeutectoid cementite allotriomorphs in hypereutectoid steels containing $1 \% \mathrm{C}$ and $1.5 \% \mathrm{Cr}$ (AISI 52100), and in some cases with phosphorous additions up to $0 \cdot 023 \%$. ${ }^{10,65,66}$ In these studies the grain boundary cementite morphology was similar to that observed by Heckel and Paxton, i.e. thin cementite films fully (or nearly fully) covering the austenite grain boundaries. ${ }^{10}$ Therefore, even at the earliest stages of transformation studied, the individual cementite crystals that had nucleated along the grain boundaries had already impinged to form essentially continuous films of cementite coating the prior austenite grain boundaries. In a later investigation, Zhou and Shiflet employed TEM and convergent beam electron diffraction to study the crystallographic orientation relationship between grain boundary cementite precipitates and the retained austenite matrix in an $\mathrm{Fe}-0 \cdot 8 \mathrm{C}-12 \mathrm{Mn}$ steel. ${ }^{26}$ Although details of the morphology were not directly discussed in that study, the published TEM micrograph ${ }^{26}$ suggests that, at least in two dimensions, the morphology was consistent with the extended grain boundary cementite films observed by prior investigators. $10,11,42,65,66$
In a TEM investigation of the effects of copper on proeutectoid cementite precipitation, the growth, morphology and internal structure of grain boundary cementite allotriomorphs in hypereutectoid $\mathrm{Fe}-1.43 \mathrm{C}$ and $\mathrm{Fe}-1 \cdot 49 \mathrm{C}-4 \cdot 9 \mathrm{Cu}$ alloys ${ }^{67}$ were studied. At very early stages of the transformation (isothermal reaction at $825^{\circ} \mathrm{C}$ for $1 \mathrm{~min}$, followed by an iced brine quench), individual, separated cementite allotriomorphs could be resolved at prior austenite grain boundaries by optical microscopy, and the 2D shapes of these precipitates appeared at that resolution to correspond to the classic 'bulged pancake' allotriomorphic morphology described earlier by Aaronson. ${ }^{1}$ These individual allotriomorphs very quickly impinged during growth, and at most other reaction times and temperatures studied the external morphology corresponded to thin films of proeutectoid cementite completely covering the austenite grain boundaries, as observed in the other studies. ${ }^{10,11,42,65,66}$ The TEM observations of these allotriomorphic films focused predominantly on the copper precipitation within the cementite, and made no further mention of the external morphology, or the presence of cementite/cementite grain boundaries within these films (i.e. internal morphology). ${ }^{67}$ A subsequent TEM investigation of copper precipitation in cementite in $\mathrm{Fe}-0 \cdot 8 \mathrm{C}-10-11 \mathrm{Mn}-1-2 \cdot 5 \mathrm{Cu}$ alloys ${ }^{56}$ provided observations of proeutectoid cementite allotriomorphs mostly at high levels of magnification, where it was difficult to infer their external morphology, although the TEM and optical micrographs presented are not inconsistent with the impinged allotriomorphic film morphology reported by earlier investigators.

A number of 3D observations of proeutectoid cementite allotriomorphs were subsequently reported in the literature. A series of deep etching studies in conjunction with both SEM and TEM analyses of the deep etched specimens in an $\mathrm{Fe}-1 \cdot 3 \mathrm{C}-13 \mathrm{Mn}$ steel $\mathrm{l}^{13,16,19,20}$ revealed that cementite allotriomorphs possessed a 3D morphology completely different from what had been deduced from past investigations of cementite that were centred about 2D observations (e.g. Ref. 1, 11, 42, 56 and 67). That is, the grain boundary cementite actually possesses a fernlike or dendritic morphology in $3 \mathrm{D}$, in which the growth of the cementite dendrite arms is predominantly confined to the austenite grain boundary planes, and do not extend significantly into the interior of the austenite grains, other than by some amount of thickening. ${ }^{13,16} \mathrm{It}$ was shown that the solid state dendrites form from the austenite matrix phase during isothermal transformation, and very rapidly impinge along the austenite boundaries to form the continuous film of cementite that is typically reported in the literature by observations on $2 \mathrm{D}$ planes of polish. ${ }^{1,10,11,16,42,65,67}$ Two and three-dimensional observations of these solid state cementite dendrites at incipient stages, intermediate (but relatively early) stages, and later stages of isothermal transformation are presented in Fig. 8.

The question arises as to how/why these dendrites were never reported in the prior literature on cementite, based on the many $2 \mathrm{D}$ observations that had been made (e.g. Ref 1, 10, 11, 42, 65 and 67). The answer is most likely related to a stereology problem, aided by a lack of resolution for many of the observations in the prior literature. As mentioned earlier, these solid state cementite dendrites remain confined to the austenite grain boundaries. In the case of $2 \mathrm{D}$ observations of 


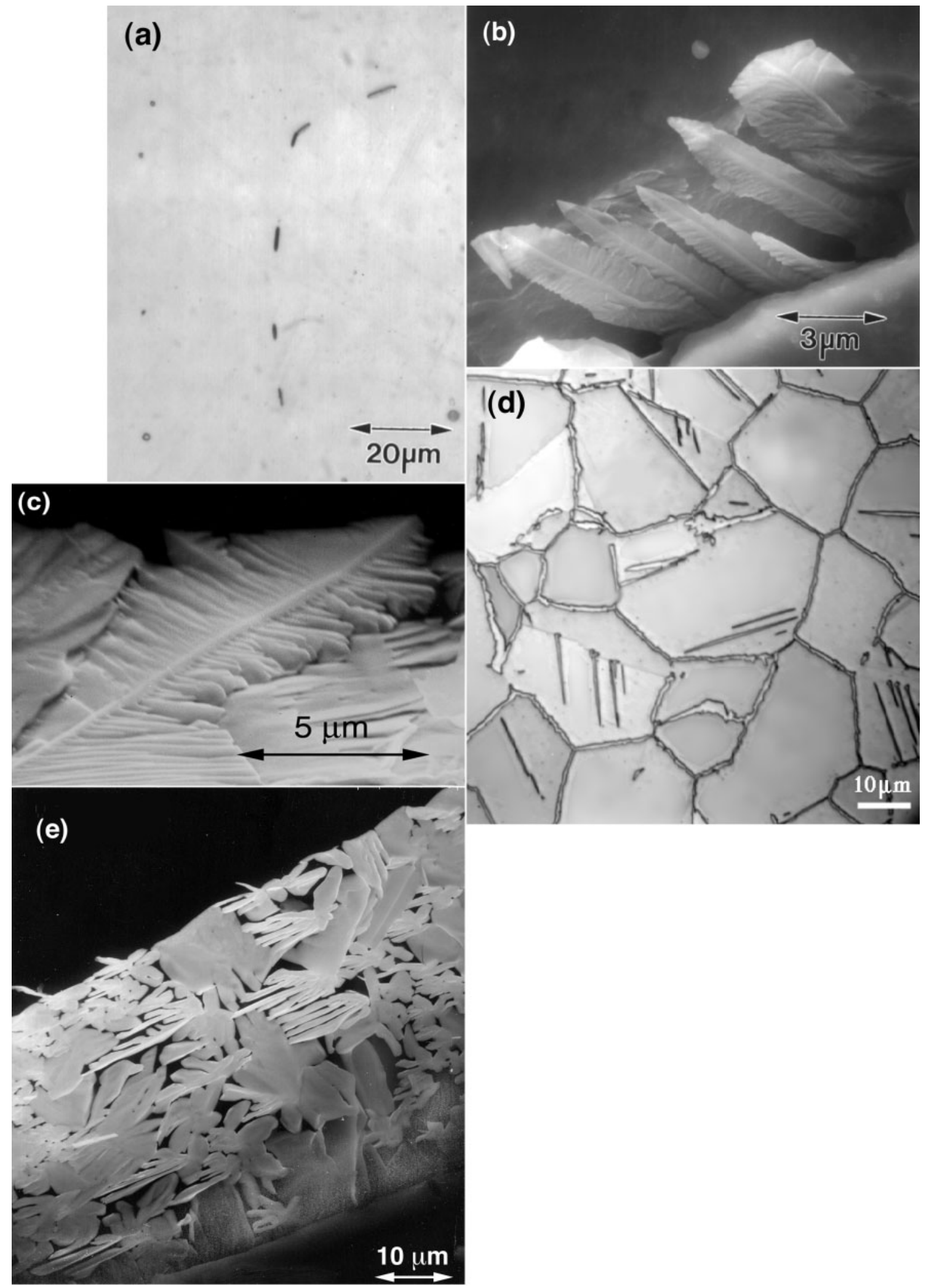

a optical micrograph of sample reacted at $650^{\circ} \mathrm{C}$ for approximately $1 \mathrm{~s}$ illustrates the typical $2 \mathrm{D}$ morphology observed for grain boundary cementite at early stages of transformation, i.e. isolated particles along austenite grain boundaries; $b$ SEM micrograph of grain boundary cementite precipitates from same specimen in a, with austenite partially deep etched away to reveal fernlike (or dendritic) morphology of these precipitates in 3D; $c$ higher magnification SEM micrograph with austenite completely deep etched away of specimen isothermally reacted for $5 \mathrm{~s}$, showing in 3D grain boundary cementite dendrites with central spine (see arrow) and secondary arms; $d$ 2D optical micrograph showing impingement of grain boundary cementite precipitates along austenite grain boundaries to from grain boundary cementite films at later stages of transformation - isothermally reacted for $50 \mathrm{~s}$; e SEM micrograph with austenite deep etched away in specimen at later stages of transformation, showing that in 3D apparent grain boundary cementite films are composed of impinged solid state cementite dendrites (a-c taken from Kral et al.., ${ }^{13}$ and $d$-e taken from Kral et al. ${ }^{16}$ )

8 Two and three-dimensional observations of solid state cementite dendrites at early, intermediate, and later stages of transformation in an $\mathrm{Fe}-1 \cdot 3 \mathrm{C}-13 \mathrm{Mn}$ alloy isothermally reacted at $650^{\circ} \mathrm{C}$ 
random planes of polish, the probability that a grain boundary plane would lie parallel to (or very nearly parallel to) the sectioning plane is minimal. The result, at very early stages of transformation before the dendrites quickly impinge to form a film, would be a $2 \mathrm{D}$ section at some glancing angle through dendrite arms, just as shown in Fig. $8 a$. Note that the same specimens shown in Fig. $8 a$ were deeply etched to reveal that those precipitates did indeed possess a solid state dendrite morphology in three dimensions (see Fig. $8 b$ and $c$ ). Precipitates such as those pictured in Fig. $8 a$ would obviously be deduced as having the shape of a 'bulged pancake ${ }^{1}$ or double spherical cap. ${ }^{63,64}$ As mentioned earlier, it has often been reported that cementite allotriomorphs in hypereutectoid alloys quickly impinge to form a continuous film of cementite along the austenite grain boundaries at relatively early stages of transformation. ${ }^{10,11,42,65,67}$ When this occurs, the 2D image is that of a continuous film as shown in Fig. 8d, and as a result of both the stereology effect just mentioned, and the limited resolution of optical microscopy, there would be no indication that in 3D these are actually impinged dendrites, as shown in Fig. $8 e$.

Finally, even with the increased resolution afforded by conventional TEM, since this involves projections through very thin (roughly $100 \mathrm{~nm}$ ) foil slices parallel to random planes in the specimen, the stereology problem just mentioned would again prevent the observation of dendrites even in conventional TEM studies, as it also would in the case of conventional SEM of $2 \mathrm{D}$ planes of polish. Although it cannot be stated unequivocally that similar $3 \mathrm{D}$ dendritic grain boundary cementite morphologies apply for many other cases in the literature in which deep etching was not (or could not be) performed (e.g. due to lack of retained austenite in the matrix), a strong argument can be made as follows. Owing to the almost identical appearance in $2 \mathrm{D}$ of the grain boundary cementite, and the nature of the cementite quickly covering the austenite grain boundaries at early stages of transformation, in both the $3 \mathrm{D}^{13,16,19,20}$ and the $2 \mathrm{D}^{10,11,42,65,67}$ studies, and the example of the correlation between $2 \mathrm{D}$ and $3 \mathrm{D}$ observations in a single specimen just provided (see also Fig. 8), it is highly likely that the grain boundary cementite in many (if not all) of the other studies ${ }^{10,11,42,65,67}$ possesses the dendritic morphology as well. It should also be noted that although the examples provided here were based on deep etching in conjunction with SEM (Fig. 8), a number of further observations of the formation mechanism and crystallography of these solid state dendrites has been made using deep etching in conjunction with TEM. ${ }^{19,20}$ These results will be considered in more detail in the relevant sections on formation mechanism and crystallography below.

It has also been reported that after the allotriomorphic cementite thickens and impinges such that the dendritic morphology is obscured and the cementite begins to resemble a film, other morphological variations can occasionally occur at longer isothermal reaction times. As summarised by Aaronson, ${ }^{1}$ ' '...with increasing time the cementite films thicken and undergo some rather profound geometrical changes'. One especially interesting form was documented by Heckel and Paxton ${ }^{11}$ as 'zig-zag forms' (see Fig. 9), which were also shown by Hultgren. ${ }^{68,69}$ It was suggested ${ }^{11,20}$ that the grain

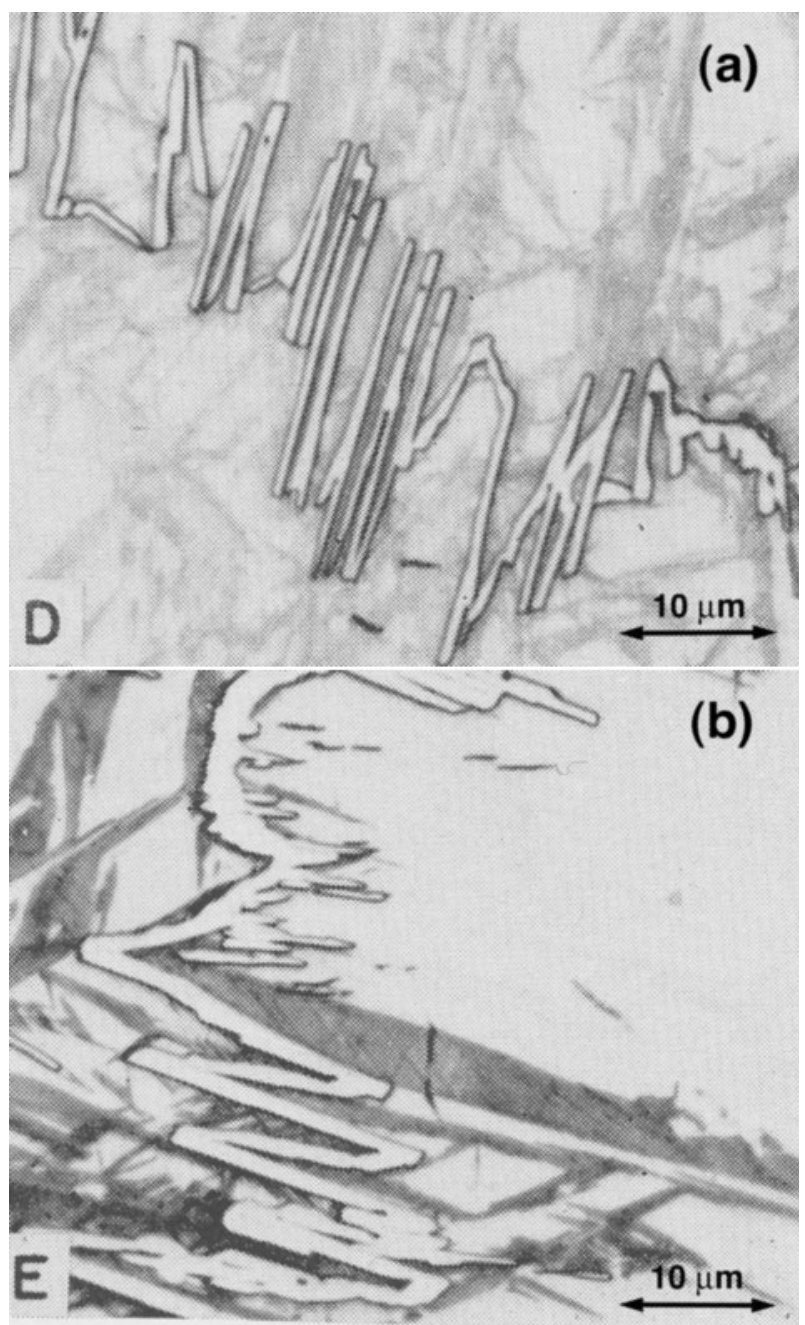

9 Optical micrographs of 'zig-zag' morphology of grain boundary cementite formed in a Fe-1.48C-0.9Mn$0.24 \mathrm{Si}$ steel reacted at $900^{\circ} \mathrm{C}$ for $90 \mathrm{~s}$, and $b \mathrm{Fe}-1.72 \mathrm{C}$ $0.9 \mathrm{Mn}-0.25 \mathrm{Si}$ steel reacted at $950^{\circ} \mathrm{C}$ for $40 \mathrm{~s}$ (taken from Heckel et al. ${ }^{11}$ )

boundary cementite films, and possibly parts of the austenite grain boundary, might migrate to minimise interfacial energies by maximising the area of low energy facets, for whatever orientation relationship is obtained. Further work is required to confirm or elucidate this migration process for the occasionally observed 'zig-zag' morphological variant.

\section{Crystallographic orientation relationships between proeutectoid cementite and austenite}

A number of orientation relationships (ORs) have been reported between proeutectoid cementite and austenite. This section will first review all of the reported ORs, and then attempt to reconcile the different observations, particularly in light of the more complete picture of proeutectoid cementite morphology presented in the last section (and described in Figs. 6-8). The OR between austenite and proeutectoid cementite has been studied by a number of investigators. ${ }^{21-26}$ The first reproducible (and still most commonly reported) OR between proeutectoid cementite and austenite was published by Pitsch in $1962,{ }^{22,23}$ based on thin foil TEM observations 
of cementite plates in an $\mathrm{Fe}-1 \cdot 28 \mathrm{C}-12 \cdot 8 \mathrm{Mn}$ steel. ${ }^{22,23}$ The published Pitsch orientation relationship was stated to be within a few degrees of

$$
\begin{aligned}
& {[100]_{\mathrm{C}} / /[5 \overline{5} 4]_{\mathrm{A}}} \\
& {[010]_{\mathrm{C}} / /[110]_{\mathrm{A}}} \\
& {[001]_{\mathrm{C}} / /[\overline{2} 25]_{\mathrm{A}}}
\end{aligned}
$$

The Pitsch OR was subsequently observed by a number of other researchers for various morphologies of proeutectoid cementite. ${ }^{12,17,20,21,26,49,55,57,58}$

In 1987, Thompson and Howell $(\mathrm{T}-\mathrm{H})$ published a different orientation relationship for what they reported by conventional thin foil TEM analyses to be intragranular cementite plates, in a hypereutectoid $\mathrm{Fe}-$ $1 \cdot 09 \mathrm{C}-2 \cdot 38 \mathrm{Mn}$ steel containing relatively small amounts of $\mathrm{Cr}, \mathrm{Si}$, and $\mathrm{Ni}^{24,47}$ This orientation relationship can be expressed as

$$
\begin{aligned}
& {[100]_{\mathrm{C}} / /[181]_{\mathrm{A}}} \\
& {[010]_{\mathrm{C}} / /[10 \overline{1}]_{\mathrm{A}}} \\
& {[001]_{\mathrm{C}} / /[\overline{4} 1 \overline{4}]_{\mathrm{A}}}
\end{aligned}
$$

Later, Thompson and Howell ${ }^{24}$ re-stated their orientation relationship and the Pitsch OR in terms of close packed planes to emphasise the potentially good atomic matching that may be responsible for these ORs

$$
\begin{array}{rr}
\text { Pitsch : }(\overline{1} 03)_{\mathrm{C}} / /(\overline{1} 1 \overline{1})_{\mathrm{A}} & \mathrm{T}-\mathrm{H}:(103)_{\mathrm{C}} / /(\overline{1} 1 \overline{1})_{\mathrm{A}} \\
{[010]_{\mathrm{C}} / /[10 \overline{1}]_{\mathrm{A}}} & {[010]_{\mathrm{C}} / /[10 \overline{1}]_{\mathrm{A}}} \\
{[\overline{3} 0 \overline{1}]_{\mathrm{C}} / /[\overline{1} \overline{1} \overline{1}]_{\mathrm{A}}} & {[\overline{3} 01]_{\mathrm{C}} / /[\overline{1} \overline{1} \overline{1}]_{\mathrm{A}}}
\end{array}
$$

Based in large part on this representation, they ${ }^{24}$ stated that the Pitsch and T-H ORs are 'apparently dissimilar' but exhibit 'surprising similarities', including a common bicrystal symmetry axis which is $[010]_{\mathrm{C}} / /[10 \overline{1}]_{\mathrm{A}}$.

Yang and $\mathrm{Choo}^{57}$ suggested that the ThompsonHowell OR is actually a variant of the Pitsch OR, which can be produced from a simple twinning operation (in the austenite), and this deduction was also later supported by Zhang and Kelly. ${ }^{25}$ However, more recently, a different set of researchers ${ }^{70}$ also suggested that the Pitsch and the $\mathrm{T}-\mathrm{H}$ ORs can be approximated by a $(101)_{\mathrm{A}}$ twin relationship. However, in contrast to some earlier studies, ${ }^{25,57}$ based on an approach combining $\Delta g^{71,72}$ and O-line ${ }^{71}$ analyses, they suggested that the T-H OR is not simply a variant of the Pitsch OR, and stated that, 'Corresponding to different ORs, the habit planes are distinct..., ${ }^{70}$ While there thus apparently remains some debate $24,47,70$ as to whether the T-H OR is actually the same as the Pitsch OR, ${ }^{25,57}$ it is nonetheless apparent that if the T-H OR is not just a different representation of the Pitsch OR, these two ORs have very many similarities. ${ }^{24}$

Farooque and Edmonds $(\mathrm{F}-\mathrm{E})^{21}$ found a completely different orientation relationship for proeutectoid Widmanstätten cementite formed in an $\mathrm{Fe}-0 \cdot 8 \mathrm{C}-12 \mathrm{Mn}$ steel, which was represented as

$$
\begin{aligned}
& {[100]_{\mathrm{C}} / /[112]_{\mathrm{A}}} \\
& {[010]_{\mathrm{C}} / /[02 \overline{1}]_{\mathrm{A}}} \\
& {[001]_{\mathrm{C}} / /[\overline{5} 12]_{\mathrm{A}}}
\end{aligned}
$$

Based on their thin foil TEM investigation, they referred to the Widmanstätten cementite possessing this OR as having a plate morphology. ${ }^{21}$ Crystallographically, the Pitsch OR and the F-E OR are quite different, and cannot be brought into coincidence with one another by any small minimum angle of rotation (or simple twinning operation). In fact, it can be shown that the minimum angle of rotation to bring them into coincidence is actually $20^{\circ} .{ }^{17}$

Zhou and Shiflet $(\mathrm{Z}-\mathrm{S})^{26}$ also subsequently reported a new OR between proeutectoid cementite and austenite, for grain boundary proeutectoid cementite allotriomorphs formed in an $\mathrm{Fe}-0 \cdot 8 \mathrm{C}-12 \mathrm{Mn}$ steel. In particular, in addition to observing the Pitsch OR for the grain boundary proeutectoid cementite allotriomorphs they studied, they observed a new OR which they represented as

$$
\begin{aligned}
& {[100]_{\mathrm{C}} / /[23 \overline{1}]_{\mathrm{A}}} \\
& {[010]_{\mathrm{C}} / /[013]_{\mathrm{A}}} \\
& {[001]_{\mathrm{C}} / /[5 \overline{3} 1]_{\mathrm{A}}}
\end{aligned}
$$

Zhou and Shiflet stated that the idealised, relatively low index parallelisms they used to represent their OR (see Table 1) were not exact, but within a few degrees $\left(<5^{\circ}\right)$ of what was observed, and also mentioned that observations from different areas showed a small amount of scatter about their published parallelisms. ${ }^{26}$ Along these lines, it was later pointed out by other researchers ${ }^{20}$ that considering such experimental uncertainty, in combination with similar experimental uncertainty reported by Farooque and Edmonds for their idealised/low index representation of the F-E OR ${ }^{21}$ about $3^{\circ}$, the $\mathrm{Z}-\mathrm{S}$ OR appears to be within the experimental scatter observed for grain boundary precipitates shown to approximate the F-E OR:20 this was also represented graphically. ${ }^{20}$ It was also pointed out $^{20}$ that the $\left\langle 100>_{\mathrm{C}}\right.$ poles in the idealised/low index $\mathrm{Z}-\mathrm{S}$ parallelisms are within $8-11^{\circ}$ of those in the idealised F-E OR. Thus, it appears that due to the relatively close proximity of the $\mathrm{Z}-\mathrm{S}$ and $\mathrm{F}-\mathrm{E}$ ORs combined with the experimental scatter observed for grain boundary proeutectoid cementite allotriomorphs, ${ }^{20,26}$ there is no discrepancy in reports of both the Z-S and F-E ORs for grain boundary cementite allotriomorphs ${ }^{20,26}$ (whose shape has more recently been shown to be that of solid state dendrites in $3 \mathrm{D}$, see the section above on morphology).

In an EBSD study of an Fe-1.34C-13Mn alloy of the orientation relationship of grain boundary proeutectoid cementite crystals possessing a dendritic allotriomorphic morphology in 3D, ${ }^{20}$ roughly $75 \%$ of the 194 grain boundary cementite precipitates studied approximated one of the known orientation relationships, i.e. Pitsch, $\mathrm{F}-\mathrm{E}$ or $\mathrm{T}-\mathrm{H}$, with respect to at least one of their adjacent austenite grains. Of the other roughly $25 \%$ of grain boundary cementite precipitates which deviated by more than $10^{\circ}$ from any of the known orientation relationships with either adjacent grain (viewed in 2D), it was suggested that this lack of an apparent OR may well have been due to fact that the cementite precipitates nucleated at grain edges or grain corners not apparent in the 2D plane of polish from which the EBSD analysis was performed. ${ }^{20}$ This possibility will be considered 
further in the section on 'Formation mechanism(s)' below.

Zhang and Kelly $(\mathrm{Z}-\mathrm{K})^{15,25}$ later used convergent beam electron diffraction (CBED) to report what they suggested to be a new OR for proeutectoid cementite. Specifically, in four hypereutectoid, high Mn (13$20 \% \mathrm{Mn}$ ) steels they examined what were termed intragranular Widmanstätten cementite plates and grain boundary nucleated sideplates - these morphological observations were apparently based on conventional TEM imaging. The OR they reported was stated as

$$
\begin{aligned}
& (100)_{\mathrm{C}} / /(\overline{1} \overline{1} 1)_{\mathrm{A}} \\
& {[100]_{\mathrm{C}} / /[112]_{\mathrm{A}}} \\
& {[011]_{\mathrm{C}} / /[\overline{1} 10]_{\mathrm{A}}}
\end{aligned}
$$

It can be shown that the $\mathrm{Z}-\mathrm{K}$ OR is within $\sim 2^{\circ}$ of the 'idealised' F-E OR. Since Farooque and Edmonds expressed the cementite-austenite OR as within $3^{\circ}$ of the 'idealised' low index parallelisms they published, ${ }^{21}$ the $\mathrm{Z}-\mathrm{K}$ OR is within the experimental variation reported for the $\mathrm{F}-\mathrm{E}$ orientation relationship, but was obtained with more accurate measurement techniques. While the parallelisms expressed in the $\mathrm{Z}-\mathrm{K}$ refinement are in some ways more physically significant (in terms of good atomic matching) and technically 'more correct', the $\mathrm{Z}-\mathrm{K}$ OR is essentially a refinement of the earlier reported $\mathrm{F}-\mathrm{E}$ OR, and thus henceforth the $\mathrm{F}-\mathrm{E}$ OR will be referred to in this paper for crystallographic relationships approximating these ORs, to avoid potential confusion on the matter.

The distinct ORs that have been observed experimentally are thus summarised in Table 1 , represented in a common form as the three directions in the austenite that are parallel to the three $<100\rangle$ type directions in the cementite, within the number of angular degrees of variance either specified by the authors or dictated by the experimental technique employed.

A critical breakthrough in reconciling some of these apparently diverse observations was made in a study that directly related the 3D morphology of Widmanstätten proeutectoid cementite precipitates to their OR with the austenite matrix. ${ }^{17}$ Electron backscatter diffraction orientation relationship analysis was applied to specific precipitates, followed by observation in SEM after deep etching of the exact same precipitates from which the OR's were determined. This work provided, for the first time, a direct correlation between the 3D morphology and the OR. Widmanstätten cementite precipitates were observed to have one of two significantly different 3D morphologies (as discussed above), either (i) monolithic plates sometimes stacked in a face to face arrangement (see Fig. 6c), or (ii) conglomerates of many laths typically arranged in an edge to edge fashion (Fig. 7c). In every case of the more than 200 cementite precipitates analysed, those that obtained a monolithic plate morphology were shown to consistently exhibit the Pitsch OR, while the conglomerates of laths always obeyed the F-E OR. This work thus clarified the underlying reason for the reports of different ORs for Widmanstätten cementite in the literature. ${ }^{17}$ In light of this study, ${ }^{17}$ it is suggested here that many of the past observations of different ORs for Widmanstätten cementite are thus related to the fact that Widmanstätten proeutectoid cementite precipitates which exhibit the Pitsch OR are monolithic plates in 3D, while those exhibiting the F-E OR are aggregates of lath shaped subunits in $3 \mathrm{D}$, but this morphological differentiation was usually not possible with the $2 \mathrm{D}$ techniques typically employed in the past (e.g. see Refs. 12, 15, $21,24,25,41,47-49$ and 55-58).

\section{Habit plane, growth direction and interfacial structure of proeutectoid cementite precipitates}

After the morphology and orientation relationships of proeutectoid cementite have been evaluated in detail, relationships between the morphology and crystallography will now be further examined by considering the habit plane, growth direction, and interfacial structure of proeutectoid cementite precipitates. With the benefit of hindsight, it is now possible to separate out previous observations of Widmanstätten cementite plates as opposed to Widmanstätten cementite laths. The lack of distinction of these morphologies has been the source of some confusion in the past and can now be avoided.

\section{Widmanstätten proeutectoid cementite 'plates'}

Consideration will first be given to Widmanstätten proeutectoid cementite 'plates'. The word 'plates' has been set in quotes here to include observations on what were considered to be plates based on 2D characterisation techniques alone, but now with the benefit of the subsequent $3 \mathrm{D}$ analyses are recognised to potentially have included at least some observations of laths as well. Cementite precipitates that were directly shown (using 3D characterisation techniques) to possess a plate shape in 3D will then be reviewed.

Three earlier sets of researchers ${ }^{7,8,43}$ independently used optical microscopy to show that the habit plane of proeutectoid cementite plates exhibited a great deal of scatter when plotted on an austenite stereographic projection. This scatter was so large that, based on these observations, the habit plane would be considered to be non-unique. ${ }^{49}$ As was pointed out by Heckel et al. ${ }^{43}$ this result is unexpected based on most theories of precipitate shape (e.g. Refs. 1, 7, 73 and 74), as well as experimental observations in other alloys and alloy systems (e.g. Refs. 22 and 75), since the presence of a broad face corresponding to a plate shaped precipitate is usually indicative of a habit plane of good fit between the precipitate and matrix lattices. ${ }^{74,76,77}$ It should also

Table 1 Summary of known orientation relationships between cementite and austenite (taken from Kral et al. ${ }^{20}$ )

\begin{tabular}{lllll}
\hline & $\begin{array}{l}\text { Pitsch } \\
\text { (within } 5^{\circ} \text { of) }\end{array}$ & $\begin{array}{l}\text { Thompson-Howell } \\
\text { (within } \mathbf{1} \text { or } \mathbf{2}^{\circ} \text { of) }\end{array}$ & $\begin{array}{l}\text { Farooque-Edmonds } \\
\text { (within } \mathbf{3}^{\circ} \text { of) }\end{array}$ & $\begin{array}{l}\text { Zhou-Shiflet } \\
\text { (within } \mathbf{5}^{\circ} \text { of) }\end{array}$ \\
\hline$[100]_{\mathrm{C}} / /$ & {$[5 \overline{5} 4]_{\gamma}$} & {$[181]_{\gamma}$} & {$[112]_{\gamma}$} & {$[213]_{\gamma}$} \\
{$[010]_{\mathrm{C}} / /$} & {$[110]_{\gamma}$} & {$[\overline{101}]_{\gamma}$} & {$[0 \overline{2} 1]_{\gamma}$} & {$[0 \overline{3} 1]_{\gamma}$} \\
{$[001]_{\mathrm{C}} / /$} & {$[\overline{2} 25]_{\gamma}$} & {$[41 \overline{4}]_{\gamma}$} & {$[\overline{5} 12]_{\gamma}$} & {$[513]_{\gamma}$} \\
\hline
\end{tabular}


be mentioned that in the first two studies, ${ }^{7,8}$ the habit plane was deduced by indirect optical microscopy methods, since the austenite matrix had transformed to martensite at room temperature, while the third study ${ }^{43}$ used X-ray diffraction to determine directly the orientation of the austenite from small amounts of austenite that were retained at room temperature.

Using transmission electron microscopy (TEM), Pitsch $^{22,23}$ observed significant scatter in the measured habit planes of proeutectoid cementite plates in an $\mathrm{Fe}-$ $1 \cdot 28 \mathrm{C}-12 \cdot 8 \mathrm{Mn}$ steel, but reported on the weighted average habit plane in the austenite (A), and the parallel direction in the cementite (C) according to the observed Pitsch OR, for the majority of the observations, excluding certain outliers. Now having the advantage of much more recent 3D studies which show that Widmanstätten precipitates obeying the Pitsch OR have a true plate morphology in $3 \mathrm{D}^{17}$ (see the section on 'Crystallographic orientation relationships between proeutectoid cementite and austenite'), it can be stated with confidence that the habit plane results reported by Pitsch do indeed apply to true cementite plates in 3D. He reported a $\{118\}_{\mathrm{A}}$ habit plane (normal parallel to $<1 \cdot 10$ $1>_{\mathrm{C}}$ ) for proeutectoid cementite formed at $600^{\circ} \mathrm{C}$, and a $\{227\}_{\text {A }}$ plane (normal parallel to $<1.85 \quad 0 \quad 1>_{\mathrm{C}}$ ) for cementite formed at $315^{\circ} \mathrm{C}$. For an $\mathrm{Fe}-1 \cdot 3 \mathrm{C}$ alloy transformed at $715^{\circ} \mathrm{C}$, he also reported an average weighted habit plane of $\left.(125)_{\mathrm{A}}\left(/ /<001>_{\mathrm{C}}\right)\right)^{22,23}$ The scatter in the individual observations, and the significant variation in the weighted average habit planes with temperature, is somewhat consistent with the earlier reports of a non-unique habit plane for proeutectoid cementite plates. $^{7,8,43}$

In a subsequent TEM investigation of Widmanstätten cementite in which both sideplates and intragranular laths were reported (based on essentially 2D conventional thin foil TEM observations), ${ }^{53}$ Cowley and Edmonds determined that the macroscopic habit plane varied significantly from the microscopic habit plane, due to the fact that the macroscopically observed Widmanstätten cementite precipitates (corresponding to their external morphology) were actually composed of a number of finer substructural units of small lath shaped cementite crystals, presumably formed by sympathetic nucleation. ${ }^{12,53}$ In particular, it was suggested that the effect of these substructural units was to rotate the apparent macroscopic habit plane away from the microscopic habit plane by approximately 4 $15^{\circ}$. The resultant microscopic habit plane in the austenite was reported to be within $5^{\circ}$ of $\{113\}_{\mathrm{A}}$. A corresponding conjugate plane in the cementite (or a cemenite-austenite OR) was not reported. ${ }^{53}$

Spanos and Aaronson subsequently employed conventional thin foil TEM to study in detail the interfacial structure and habit plane of the broad faces of what they reported (based on 2D observations) to be Widmanstätten proeutectoid cementite plates in an $\mathrm{Fe}-$ $0 \cdot 81 \mathrm{C}-12 \cdot 2 \mathrm{Mn}$ alloy. ${ }^{49}$ They observed the Pitsch OR between the Widmanstätten cementite and the austenite matrix, now indicating (based on the more recent 3D studies, ${ }^{17}$ and as also described above for Pitsch's work $^{22,23}$ ) that the Widmanstätten cementite precipitates they studied were truly plate shaped in $3 \mathrm{D}$. The austenite/cementite interface was shown ${ }^{49}$ to contain two types of features (i) coarse ledges with heights of about $7 \mathrm{~nm}$ and spacings between 30 and $100 \mathrm{~nm}$

(ii) finer straighter ledges with heights of $2 \mathrm{~nm}$ or less, more regular spacings between $4-6 \mathrm{~nm}$, and a reproducible line direction of $[110]_{\mathrm{A}} / /[010]_{\mathrm{C}}$.

Atomic modelling studies were also performed to elucidate conjugate parallel planes and directions of best fit between the austenite and cementite lattices obeying (or nearly obeying) the Pitsch OR. Based on their TEM analysis and these corroborative atomic modelling studies, Spanos and Aaronson ${ }^{49}$ thus deduced that the $(1 \overline{1} 3)_{\mathrm{A}} / /(101)_{\mathrm{C}}$ conjugate pair was most likely the atomic habit plane (AHP) of proeutectoid cementite plates. The atomic matching studies suggested that these conjugate planes should provide the best planar atomic fit between the austenite and cementite lattices, and that the observed $[110]_{\mathrm{A}} / /[010]_{\mathrm{C}}$ fine ledge direction represented the direction of best linear fit between the two lattices. It was suggested that the steps effectively rotate the average interface orientation from the AHP to an apparent macroscopic habit plane, which was termed the TEM apparent habit plane (TApHP), and that the TApHP can differ from the AHP by as much as a $10^{\circ}$ rotation (but usually within $5^{\circ}$ ) (see Fig. 10a). An optical apparent habit plane (OAHP) was also defined as the apparent habit plane evaluated by optical microscopy, and it was suggested that face to face sympathetic nucleation of cementite plates $^{12,13,16,17}$ could further rotate the OAHP from the AHP (see Fig. 10b). It was thus concluded that earlier reports of a non-unique habit plane for proeutectoid cementite plates ${ }^{7,8,43}$ were due to a combination of the steps at the cementite/austenite interface, and sympathetic nucleation which can give rise to an apparent habit plane which differs substantially from the unique atomic habit plane of $(113)_{\mathrm{A}} / /(101)_{\mathrm{C}} \cdot{ }^{49}$

It should be noted that these observations ${ }^{49}$ are consistent in many respects with the earlier findings of Cowley and Edmonds, who reported that the macroscopic habit plane of Widmanstätten cementite precipitates varied significantly from the microscopic interface plane due to the presence of a number of finer, presumably sympathetically nucleated substructural units, and that these substructural units rotate the apparent macroscopic habit plane away from the microscopic habit plane by between 4 and $15^{\circ} .^{53}$ They also reported that the Widmanstätten cementite habit plane was within $5^{\circ}$ of $\{113\}_{\mathrm{A}}$, in agreement with the $(1 \overline{1} 3)_{\mathrm{A}} / /(101)_{\mathrm{C}}$ atomic habit plane reported by Spanos and Aaronson, ${ }^{49}$ and discussed 'periodic image contrast' due to a 'regular array of linear defects', which could very well correspond to the fine ledges of 4-6 nm lying along the $[110]_{\mathrm{A}} / /[010]_{\mathrm{C}}$ line direction of good fit between the lattices reported in the other study. ${ }^{49}$ Some differences between the two studies ${ }^{49,53}$ are:

(i) that the cementite-austenite $\mathrm{OR}$ and conjugate habit plane in the cementite were not reported in the earlier investigation ${ }^{53}$

(ii) that that study ${ }^{53}$ focused mostly on what they described to be a lath morphology (and occasionally sideplates), whereas the other investigation $^{49}$ was centred about Widmanstätten cementite plates.

The latter apparent differences in precipitate shape may be due at least in part to the $2 \mathrm{D}$ versus $3 \mathrm{D}$ morphological conundrum discussed earlier. 

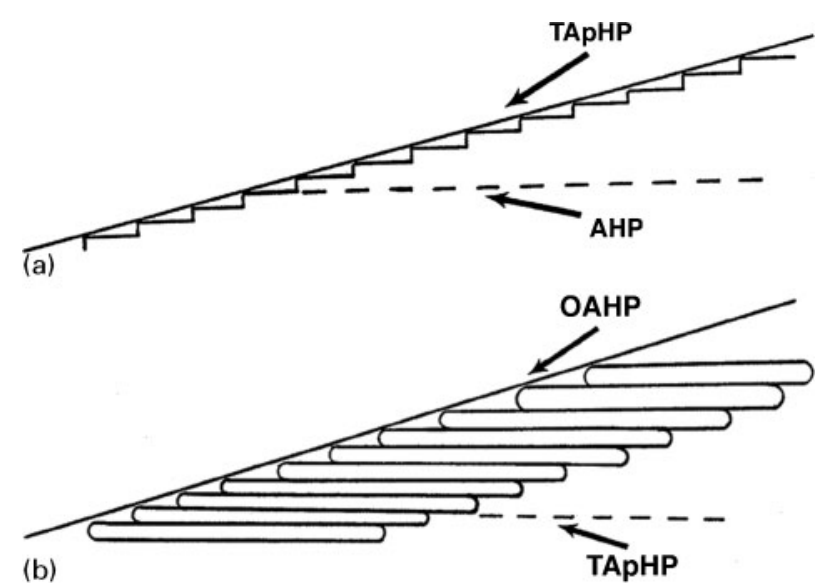

10 Schematic illustrations of a ledged interface showing relationship between apparent plane observed at conventional TEM level of resolution, and termed TEM apparent habit plane (TApHP), and the atomic habit plane (AHP) corresponding to terraces of fine ledges and $b$ relationship between TApHP and habit plane observed by optical microscopy, termed optical apparent habit plane (OAHP), resulting from aggregate of Widmanstatten cementite crystals sympathetically nucleated atop one another (taken from Spanos et al. $^{49}$ )

Subsequent TEM investigations by Khalid and Edmonds verified the possibility of a $\{113\}_{\mathrm{A}}$ habit plane and also reported 'linear striations' or linear defects at the cementite/austenite interface of Widmanstätten cementite which was reported to possess a plate morphology. ${ }^{18,55,56}$ These studies did not directly verify or refute the $(1 \overline{1} 3)_{\mathrm{A}} / /(101)_{\mathrm{C}}$ atomic habit plane or the fine ledges parallel to the $[110]_{\mathrm{A}} / /[010]_{\mathrm{C}}$ line direction of good fit reported earlier, ${ }^{49}$ since they did not measure the conjugate habit plane in the cementite, the crystallographic directions of the linear features at the interface, or ledge heights. In particular, two types of features were observed: ${ }^{18,55,56}$ coarse linear striations, and more regularly spaced sets of fringes, spaced $3-8 \mathrm{~nm}$ apart. These features seem quite similar to the coarse ledges ( $\sim 7 \mathrm{~nm}$ height and 30-100 nm spacing) and fine ledges ( $<2 \mathrm{~nm}$ height, 4-6 $\mathrm{nm}$ spacing, and $[110]_{\mathrm{A}} / /[010]_{\mathrm{C}}$ line direction) reported earlier, ${ }^{49}$ but were interpreted quite differently in the two sets of investigations (Refs. 18, 55 and 56 versus Refs. 12 and 49). Khalid and Edmonds ${ }^{55,56}$ suggested that the coarse linear defects were extrinsic features resulting from the intersection of stacking faults in the austenite with the cementite plates, ${ }^{55,56}$ while the fine linear features were attributed to intrinsic interfacial dislocations, and no comment was made as to any step or ledge character of the fine features. They also reported that, at least in copper containing hypereutectoid steels, it was unlikely that the coarse linear defects can act as growth ledges, due to the observation of the precipitation of copper particles on such features. ${ }^{56}$ On the other hand, Spanos and Aaronson ${ }^{12,49}$ suggested that the coarse ledges observed in their study were growth ledges which were often curved and contained kinks, and noted that the regularly spaced fine ledges had similarities to 'direction steps' observed on pearlite/austenite interfaces, ${ }^{78}$ and discussed both similarities and differences of these fine ledges to the 'structural ledges' observed at ferrie/austenite interfaces. ${ }^{79-81}$ The apparent differences in interpretation of these linear defects between the different sets of investigators (Refs. 18, 55 and 56 versus Refs. 12 and 49) could be related to differences in alloy composition or transformation temperatures, but will nonetheless be considered in more detail below, in a discussion of a high resolution TEM investigation of the atomic structure of cementite/austenite interfaces, ${ }^{58}$ as well in the section below on 'Formation mechanism(s) of proeutectoid cementite'.

In a conventional TEM investigation of the habit plane of what was reported to be an intergranularly nucleated cementite plate which obeyed the 'Pitschlike ${ }^{48} \mathrm{~T}-\mathrm{H}$ OR, Thompson and Howell ${ }^{48}$ determined that the microscopic habit plane corresponding to the broad face of the Widmansatten cementite crystal studied was $(\overline{33} 7)_{\mathrm{A}} / /(30 \overline{4})_{\mathrm{C}}$, and noted that this was very close to the $(1 \overline{1} 3)_{\mathrm{A}} / /(101)_{\mathrm{C}}$ habit plane reported earlier by other researchers. ${ }^{49}$ They also observed two sets of linear features:

(i) coarse ledges measuring $3 \mathrm{~nm}$ in height and $\sim 40 \mathrm{~nm}$ in spacing;

(ii) a finer set of interfacial features spaced $3 \mathrm{~nm}$ apart but that were difficult to resolve, and they stated that these interfacial structure results 'compared favourably' with those of the earlier study. 49

Zhang and Kelly ${ }^{15}$ applied 'edge to edge matching' analysis to Widmanstätten proeutectoid cementite precipitates in austenite (use of the term 'edge to edge' here should not be confused with the earlier description of 'edge to edge' sympathetic nucleation, as it has a completely different meaning in the crystallographic context used here by Zhang and Kelly $)^{15}$. Edge to edge matching is a crystallographic approach to understanding habit planes and precipitate morphologies, based on the concept that interfacial energy is minimised when rows of atoms match across an interface. In cementite obeying the Pitsch OR with the austenite matrix, their analysis verified the best fit atomic habit plane, $\{113\}_{\mathrm{A}} / /$ $\{101\}_{\mathrm{C}}$, the good fit direction, $<110>_{\mathrm{A}} / /<010>_{\mathrm{C}}$, and even the secondary direction of good fit in the atomic habit plane, $\left\langle 101>_{\mathrm{A}} / /<332>_{\mathrm{C}}\right.$, that had been determined earlier ${ }^{49}$ using a combination of experimental and plane on plane atomic matching techniques. Zhang and Kelly showed the usefulness of considering the edge to edge matching of close packed planes in the two lattices, i.e. $\{103\}$ or $\{022\}$ for cementite, and $\{111\}$ for austenite. They also applied this analysis to cementite precipitates obeying the Zhang-Kelly refinement of the Farooque-Edmonds OR (Z-K/F-E OR) to show that the good fit direction in this $\mathrm{OR}$ is $<112>_{\mathrm{A}} / /<100>_{\mathrm{C}}$, and that the atomic habit plane for the $\mathrm{Z}-\mathrm{K} / \mathrm{F}-\mathrm{E}$ OR, which they also determined experimentally by using TEM trace analysis techniques, was within a few degrees of $\{421\}_{\mathrm{A}} / /\{015\}_{\mathrm{C}}$. The latter results on good fit direction and habit plane for cementite precipitates obeying the $\mathrm{Z}-\mathrm{K} / \mathrm{F}-\mathrm{E}$ OR will also be considered further in the discussion of cementite laths below (section on 'Widmanstätten proeutectoid cementite 'laths").

High resolution transmission electron microscopy (HRTEM) was employed to investigate directly the atomic structure at the broad face of Widmanstätten cementite plates formed in an $\mathrm{Fe}-1 \cdot 3 \mathrm{C}-13 \mathrm{Mn}$ alloy. ${ }^{58}$ These Widmanstätten precipitates were shown to obey 
the Pitsch OR, ${ }^{58}$ again confirming that they possessed a plate shape in $3 \mathrm{D}$ as well as in $2 \mathrm{D} .^{17}$ The HRTEM observations confirmed, at the atomic level, three observations deduced by conventional TEM analysis in conjunction with atom matching models in the earlier study ${ }^{49}$, namely

(i) a $(1 \overline{1} 3)_{\mathrm{A}} / /(101)_{\mathrm{C}}$ atomic habit plane corresponding to ledge terraces

(ii) fine ledges lying along the $[110]_{\mathrm{A}} / /[010]_{\mathrm{C}}$ direction

(iii) an average habit plane at the broad face of the Widmanstätten cementite that is inclined with respect to the $(1 \overline{1} 3)_{\mathrm{A}} / /(101)_{\mathrm{C}}$ atomic habit plane, due to the presence of the ledges at the interface (see Fig. 11).

A number of other important findings were reported in this HRTEM study, ${ }^{58}$ including observation that the fine ledge height was $0 \cdot 38 \mathrm{~nm}$, the ledge 'riser' or plane connecting the fine ledge terraces was not orthogonal to the terraces, but instead lay along $(1 \overline{1} 3)_{\mathrm{A}} / /(001)_{\mathrm{C}}$ (see Fig. 11b), and a pair of edge dislocations nearly perpendicular to each other was associated with each fine ledge (Fig. 11c). It was shown that the geometry of these dislocation pairs was such that one or both would have to climb in order for the austenite/cementite interface in the vicinity of these ledges to migrate. The ledges were also shown to be intrinsic features of the interface that in most cases were not associated with intersections of faults or other defects with the austenite/cementite interface. Even though many ledges without associated stacking faults were observed, in some cases stacking faults were found to emanate from the ledges into the austenite matrix, as opposed to the intersection of the stacking faults with the austenite/cementite interface causing the ledges. This was evidenced in part by examples of multiple stacking faults emanating in different directions (on different planes) from a single ledge, and often terminating in the austenite matrix at relatively short distances from the ledge. It was suggested that the stacking faults may form at the ledges at least in part to help accommodate misfit at the interface, which was consistent with the observation of strain lobes associated with the ledges. ${ }^{58}$

Zhang and coworkers ${ }^{70,82}$ subsequently applied a combination of $\Delta g,{ }^{71,72} \mathrm{O}$-line, ${ }^{76}$ coincidence site lattice (CSL) ${ }^{83}$ displacement shift complete lattice (DSCL), ${ }^{83,84}$ and constrained CSL and $\mathrm{DSCL}^{84-86}$ analyses to model the habit planes and interfacial features of Widmanstätten cementite for both the Pitsch and T-H ORs and compared their results to two experimental studies (Refs. 58 and 48) respectively. For the Pitsch OR, they reported that the calculated atomic habit plane corresponding to ledge terraces, the average habit plane, the fine ledge direction, the ledge heights, the ledge spacings and the interfacial dislocations were all consistent with those measured experimentally. ${ }^{58}$ It should be mentioned here that they ${ }^{70,82}$ may have overemphasised the importance of the 'average habit plane' of $(11 \overline{4})_{\mathrm{A}} / /(504)_{\mathrm{C}}$ reported in the experimental study ${ }^{58}$ as follows. In the experimental study, ${ }^{58}$ it was shown that this was the average habit plane measured in one local region of one interface, and that the average or apparent habit plane measured at the conventional TEM level (the TApHP) varies
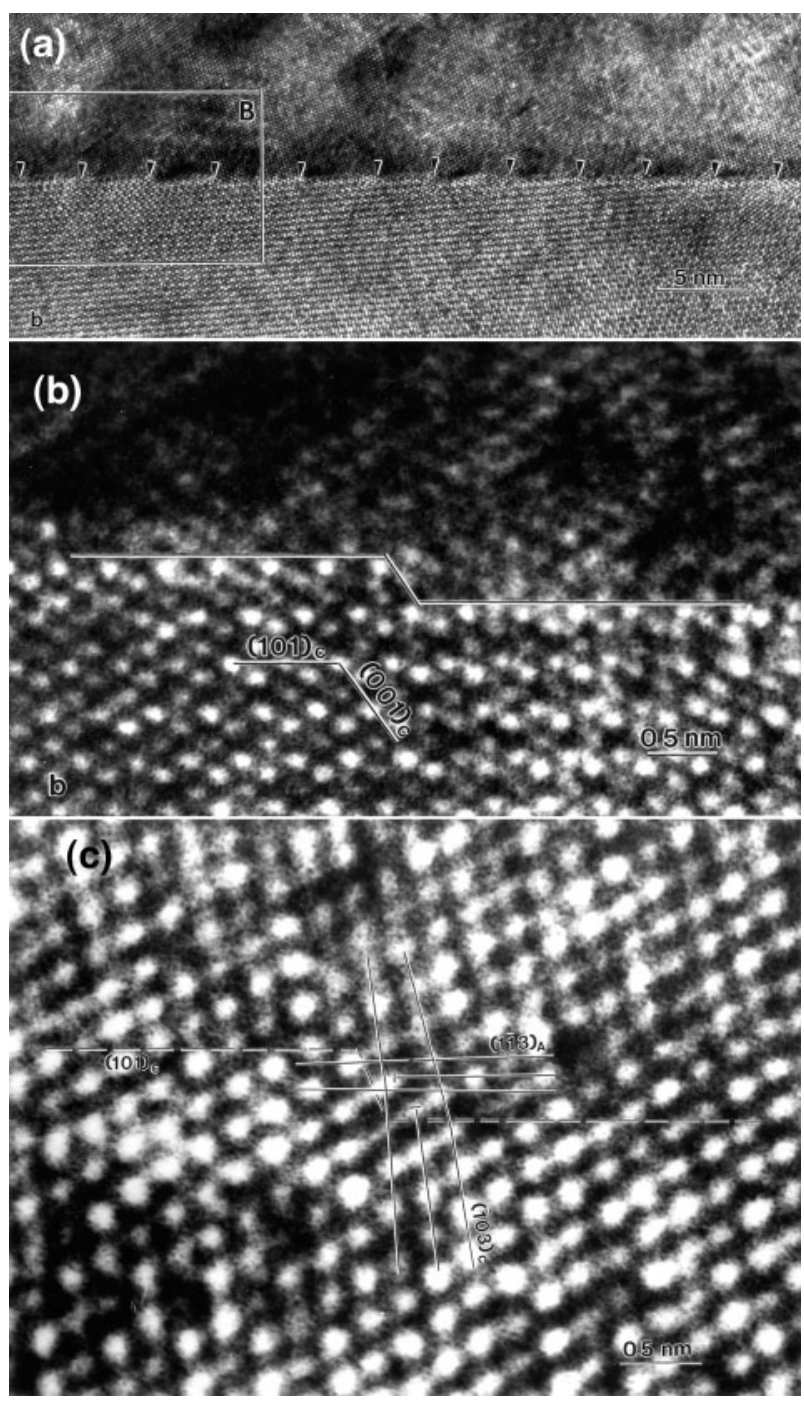

11 High resolution TEM micrographs taken from $\mathrm{Fe}$ $1 \cdot 34 \mathrm{C}-13 \mathrm{Mn}$ alloy isothermally reacted at $650^{\circ} \mathrm{C}$ for $100 \mathrm{~s}$, showing: $a$ a series of fine ledges (spaced about $3.7 \mathrm{~nm}$ apart) at austenite/cementite interface (austenite on top, cementite on bottom) corresponding to the broad face of the proeutectoid cementite plate, $b$ enlargement from one of arrowed ledges in region B of $a$, showing (001)c ledge riser plane, which connects upper and lower (101)c terrace planes, $c$ high resolution image from another ledge in very thin region of TEM foil, showing, in addition to positions of $(101)_{C} /(1 \overline{1} 3)_{A}$ ledge terrace and $(001)_{C}$ ledge riser planes, positions of terminating $\left(\mathbf{1 0 3}_{\mathrm{C}}\right.$ plane and terminating $(1 \overline{13})_{A}$ plane, corresponding to two edge dislocations associated with ledge (taken from Howe et $a .^{58}$ )

significantly across different regions of single Widmanstätten cementite plates as well as among different plates, due to changes in the local ledge spacing; whereas, the atomic habit plane was always uniquely $(\overline{1} 13)_{\mathrm{A}} / /(101)_{\mathrm{C}}{ }^{49,58}$

Zhang and coworkers ${ }^{70,82}$ also showed that their results for the $\mathrm{T}-\mathrm{H}$ OR resulted in the same atomic habit plane as the one calculated for the Pitsch OR, and reported experimentally by previous researchers for precipitates obeying the Pitsch $\mathrm{OR}^{49,58}-$ $(113)_{\mathrm{A}} / /(101)_{\mathrm{C}}$. This habit plane is relatively close to 
the $\{337\}_{\mathrm{A}} / /\{304\}_{\mathrm{C}}$ habit plane reported by Thompson and Howell. ${ }^{48}$ They also showed that the observation of fine linear features (and their measured spacings) by Thompson and Howell ${ }^{48}$ could be accounted for by their modelling. $^{82}$

In a predominantly TEM study of Widmanstätten cementite, Fonda et al. ${ }^{87}$ employed a 3D near coincidence site or moiré model ${ }^{88,89}$ in order to predict growth directions and habit planes, mostly for lath shaped proeutectoid cementite precipitates obeying the $\mathrm{Z}-\mathrm{K}$ refinement of the $\mathrm{F}-\mathrm{E}$ OR. In the course of their investigation though, they also performed similar modelling for proeutectoid cementite precipitates obeying the Pitsch OR, which is applicable in the present context to Widmanstätten cementite plates. In the latter case, they showed that both the direction and the plane of good atomic matching corresponded well with the those reported in the earlier experimental investigations, i.e. the $[110]_{\mathrm{A}} / /[010]_{\mathrm{C}}$ fine ledge direction, and the $(\overline{1} 13)_{\mathrm{A}} / /(101)_{\mathrm{C}}$ atomic habit plane corresponding to ledge terraces. ${ }^{49,58}$

\section{Widmanstätten proeutectoid cementite 'laths'}

Consideration will now be given to studies of the growth direction, habit plane, and interfacial structure of Widmanstätten proeutectoid cementite laths. Deep etching in conjunction with TEM was employed in an $\mathrm{Fe}-1 \cdot 3 \mathrm{C}-13 \mathrm{Mn}$ steel to study the primary growth direction of cementite precipitates which were shown to possess a lath morphology in $3 \mathrm{D} .{ }^{90}$ By performing bright field TEM imaging, selected area diffraction (SAD), convergent beam electron diffraction (CBED), and trace analysis on deep etched specimens, it was determined that the primary growth direction (i.e. the long dimension) of Widmanstätten cementite laths, which obeyed the F-E OR, was consistently $[100]_{C}$. Additionally, it was shown that in most cases studied, the broad faces of the laths had a habit plane that was oriented close to $(001)_{\mathrm{C}}$.

In a subsequent investigation, ${ }^{87}$ conventional and high resolution TEM were additionally employed to investigate the growth direction, habit plane, and interfacial structure of proeutectoid cementite laths (in 3D) in the same alloy, but with higher resolution techniques and full retention of the austenite matrix, as compared to the earlier deep etching TEM study. ${ }^{90}$ The $\mathrm{Z}-\mathrm{K}$ refinement of the $\mathrm{F}-\mathrm{E}$ OR was observed for all of the laths, and the $[100]_{\mathrm{C}}$ lath growth direction was verified (see Fig. 12a). It should be noted here that $[100]_{\mathrm{C}}$ was found to be parallel to $[112]_{\mathrm{A}}$, as it was in the original description of the $\mathrm{F}-\mathrm{E} \mathrm{OR}^{21}$ as well as in the Z$\mathrm{K}$ refinement of the F-E OR. ${ }^{25}$ The broad face, or habit plane of the laths was shown to vary from 10 to $15^{\circ}$ from the $(001)_{C}$ plane, in general agreement with the results of the earlier deep etching study. ${ }^{90}$ The broad faces of the cementite laths were shown to contain a complex interfacial structure consisting of three types of features:

(i) direction steps (fine ledges which change the average direction of the habit plane)

(ii) another set of misfit compensating defects described as either misfit dislocations or structural ledges

(iii) a coarser set of curved features which were interpreted as either growth ledges or intruder dislocations from the austenite matrix which
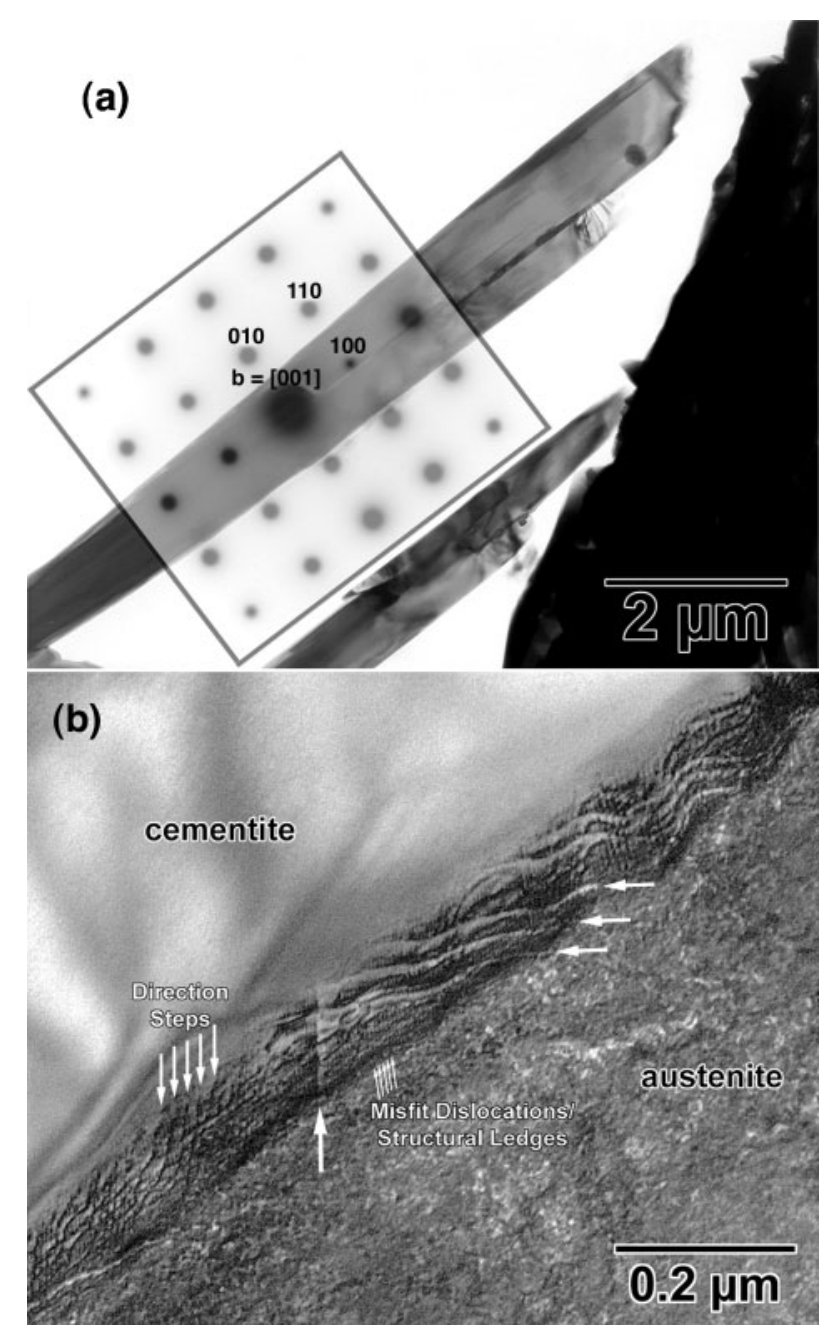

a TEM micrograph and corresponding superimposed diffraction pattern from specimen in which austenite was deep etched away and lath was viewed perpendicular to its broad face, indicating that lath long axis is parallel to $[100]_{c}$ direction; $b$ conventional thin foil specimen showing interfacial defects at cementite lath broad face: labeled arrows indicate direction steps that change the orientation of the boundary and misfit compensating defects, while three unlabeled arrows at upper right are coarser set of curved defects which were interpreted as either growth ledges or intruder dislocations (taken from Fonda et al. ${ }^{87}$ )

12 Micrographs (TEM) taken from Fe-1.34C-13Mn alloy isothermally reacted at $650 \mathrm{C}$ for $30 \mathrm{~s}$

intersect the austenite/cementite interface (see Fig. 12b).

It is noted here that intruder dislocations that have a Burger's vector component normal to the interface can produce interfacial ledges that might then be adopted as growth ledges. The 3D near coincidence analysis ${ }^{88,89}$ for cementite obeying the $\mathrm{Z}-\mathrm{K}$ refinement of the $\mathrm{F}-\mathrm{E}$ OR with the austenite showed that the good fit direction lay along [100] in the cementite, which in both the F-E OR and the $\mathrm{Z}-\mathrm{K}$ OR is parallel to the [112] direction in the austenite, but it was noted that the coincidence was not 'continuous' in this direction, such that a direction analogous to an invariant line or O-line was not observed in the modelling. Nevertheless, the predicted $[100]_{C} / /[112]_{A}$ direction of good fit agreed very well with the experimental observation of the $[100]_{\mathrm{C}}$ lath growth 
direction (or lath long axis). ${ }^{87,90}$ On the other hand, in the $\mathrm{Z}-\mathrm{K}$ refinement of the $\mathrm{F}-\mathrm{E}$ OR the $3 \mathrm{D}$ near coincidence site modelling did not reveal a single moiré plane with significantly better atomic matching than all others, and it was suggested that this may be responsible for the experimental observation of the lack of a well defined habit plane for the cementite laths obeying this OR. On the other hand, the model did show some near coincidence site clustering parallel to $(001)_{\mathrm{C}}$, along with other planes as well. These results are also consistent with the experimental observations of lath broad faces varying from about 10 to $15^{\circ}$ about the $(001)_{\mathrm{C}}$ plane. ${ }^{87,90}$

Although Zhang and Kelly ${ }^{15}$ described the Widmanstätten cementite precipitates for which they determined a habit plane as 'plates', their results will now be reconsidered here in relation to observations of cementite laths in $3 \mathrm{D}$ by other investigators. They ${ }^{15}$ reported that the Widmanstätten proeutectoid cementite precipitates they observed obeyed the $\mathrm{Z}-\mathrm{K}$ refinement of the F-E OR. In light of the fact that subsequent $3 \mathrm{D}$ investigations have shown that proeutectoid Widmanstätten cementite precipitates that are lath shaped in $3 \mathrm{D}$ typically obey the $\mathrm{F}-\mathrm{E}$ (or Z-K) OR, ${ }^{17}$ it is probable that the Widmanstätten cementite precipitates observed by Zhang and Kelly were actually conglomerates of fine lath shaped subunits in $3 \mathrm{D}$, which have often been shown to appear as plates when viewed on 2D planes of polish only, or when viewed in essentially 2D thin foil TEM specimens. ${ }^{16,17,19,20}$ If considered in this light, Zhang and Kelly's results are very consistent with the observations of Fonda et al. for Widmanstätten cementite shown to possess a lath morphology in 3D. For example, Zhang and Kelly's good fit direction, $<112>_{\mathrm{A}} / /<100>_{\mathrm{C}}$, is the same as both the experimentally measured lath growth direction, and the good fit direction modelled by a 3D near coincidence site model in the other study. ${ }^{87}$ Additionally, the habit plane measured by Zhang and Kelly, $\{421\}_{\mathrm{A}} / /\{015\}_{\mathrm{C}}$, is calculated here (based on the lattice parameters for cementite reported in that study ${ }^{15}$ ) to be within $15^{\circ}$ of $(001)_{\mathrm{C}}$, which is consistent with the experimental observations in the other studies of cementite lath broad faces varying from $\sim 10$ to $15^{\circ}$ from $(001)_{\mathrm{C}} \cdot{ }^{87,90}$

\section{Grain boundary cementite}

Significantly fewer studies have been made of the growth direction, habit plane, and/or interfacial structure of proeutectoid cementite that forms and grows along austenite grain boundaries. In a study by Ando and Krauss of grain boundary cementite growth in $1 \mathrm{C}-1 \cdot 5 \mathrm{Cr}$ steels, ${ }^{10}$ a combination of SEM of fractured cementite/ austenite interfaces and corroborative conventional thin foil TEM were employed to determine the structure of cementite/austenite interfaces at grain boundary cementite allotriomorphs (see the discussion in the section on morphology above, where grain boundary proeutectoid cementite 'allotriomorphs' have been shown in other hypereutectoid steels to correspond to solid state dendrites in three dimensions). It was shown that the cementite/austenite interfaces contained a large number of coarse and fine ledges, and from the micrographs it appeared that a number of the ledges had kinks upon them. In conjunction with growth kinetics studies, it was deduced that these interfaces move by the lateral migration of the ledges, ${ }^{10}$ i.e. by a ledge mechanism of growth. ${ }^{1}$

In a subsequent study by Wasynczuk et al. of the effects of copper on precipitation of grain boundary cementite in $\mathrm{Fe}-1 \cdot 43 \mathrm{C}$ and $\mathrm{Fe}-1 \cdot 49 \mathrm{C}-4 \cdot 90 \mathrm{Cu}$ alloys, ${ }^{67}$ although direct observation of the details of the cementite/austenite interfaces was not possible due to transformation of the austenite matrix to martensite during the quench to room temperature, interfacial structure details were deduced by the kinetics of the cementite transformation in combination with TEM observations of the morphology and distribution of copper particles precipitated in association with the cementite. In particular, the larger copper precipitates observed within the cementite were often arranged in linear arrays or sheets, similar to the interphase boundary carbides formed in association with ledges at ferrite/austenite interfaces. ${ }^{91-94}$ Based on both the kinetic and structural observations, it was suggested that the copper precipitated at partially coherent facets at the cementite/austenite interfaces, similar to the interphase boundary precipitation at ledged interfaces. ${ }^{67}$ This is consistent with the earlier observations by other investigators of ledges at grain boundary cementite/ austenite interfaces in $1 \mathrm{C}-1 \cdot 5 \mathrm{Cr}$ steels. ${ }^{10}$

In a later TEM study by Khalid and Edmonds in two hypereutectoid alloys containing $0 \cdot 8 \% \mathrm{C}, 10-11 \% \mathrm{Mn}$, and copper additions of $1 \cdot 5 \%$ and $2 \cdot 6 \%$ respectively, ${ }^{56}$ the austenite matrix could be retained directly at room temperature, due to the high levels of $\mathrm{Mn}$, which helped to suppress the martensite start temperature to below room temperature. Rows of copper precipitates in grain boundary cementite were again observed, and it was suggested that they formed by interphase boundary precipitation, but in this case the ledges at the cementite/ austenite interfaces were also directly imaged in the TEM, along with the rows of copper precipitates formed at the interface. These results are consistent with the previous observations and deductions of ledges at the cementite/austenite interphase boundaries of grain boundary cementite formed in other hypereutectoid alloys. ${ }^{10,67}$ It was also reported that the rows of copper precipitates often lay parallel to (001) planes in the cementite, which in the published micrograph corresponded to a large $(001)_{\mathrm{C}}$ facet at the cementite/austenite interface. $^{56}$

TEM trace analysis in conjunction with deep etching was subsequently employed in an $\mathrm{Fe}-1 \cdot 3 \mathrm{C}-13 \mathrm{Mn}$ steel to determine the growth direction(s) of grain boundary cementite allotriomorphs which were shown to have the shape of solid state dendrites in $3 \mathrm{D} .{ }^{20}$ The results indicated that there was no unique primary dendrite arm growth direction among the 12 deeply etched grain boundary cementite precipitates for which detailed trace analysis was performed. This was suggested to be related to the fact that the crystallographic constraints on cementite growth are relaxed within the more open structure of the austenite grain boundaries, thus helping to allow the solid state dendrites to form in the first place, and that on a finer level this is most likely due to the relative ease of growth ledge and kink formation along cementite/austenite interfaces. ${ }^{20}$ Alternatively, it was also noted that three of the 12 cementite dendrites for which trace analysis was performed had a primary dendrite arm growth direction of [010] in the cementite. 
A possible explanation put forth for this observation ${ }^{20}$ was that these three precipitates may have obeyed the Pitsch OR with respect to at least one of the austenite grains, and thus the grain boundary plane contained the good fit $[110]_{\mathrm{A}} / /[010]_{\mathrm{C}}$ direction observed for proeutectoid cementite plates. ${ }^{4,58}$ This is consistent with the EBSD observation in the same study ${ }^{20}$ (on other specimens which were not deeply etched) that roughly $25 \%$ of the 194 grain boundary cementite precipitates from which the cementite-austenite OR was measured possessed the Pitsch OR with respect to at least one of the adjacent austenite grains. It must be noted though that for the aforementioned three precipitates possessing a $[010]_{\mathrm{C}}$ primary dendrite arm direction, there is no direct evidence for a link between the $[010]_{C}$ primary growth direction of the grain boundary cementite and the orientation relationship it might assume with either adjacent austenite grain, since the process of etching away the austenite matrix in that study precluded such an analysis. ${ }^{20}$

\section{Growth kinetics}

Although many more studies have been performed on the growth kinetics of proeutectoid ferrite than on proeutectoid cementite in steels, there have been a few quantitative investigations of the migration rate of proeutectoid cementite/austenite interfaces during growth. Much of this type of experimental information has been previously summarised in a paper on the role of ledges in the proeutectoid ferrite and proeutectoid cementite transformations, ${ }^{95}$ from which a number of the details provided below will be taken. Such findings will also be considered here though in light of the newer observations on morphology, orientation relationships, crystallographic habit planes and growth directions, and interfacial structure discussed in detail above. Consideration will first be given to the growth kinetics of Widmanstätten proeutectoid cementite morphologies (e.g. plates, laths or rods).

\section{Widmanstätten cementite}

Heckel and Paxton ${ }^{42}$ measured the lengthening rates of proeutectoid cementite plates formed isothermally at various temperatures in the range between 700 and $1000^{\circ} \mathrm{C}$ in plain carbon steels containing $1 \cdot 20,1 \cdot 48$ and $1.72 \%$ C. They reported experimentally observed lengthening rates that were consistently several orders of magnitude below predicted growth rates calculated using the Zener-Hillert model ${ }^{96,97}$ for volume-diffusion controlled growth assuming ledge free disordered cementite/austenite interfaces. It was suggested that this discrepancy was due to a combination of silicon buildup in the austenite at the cementite/austenite interfaces, as well as to non-equilibrium interface conditions (i.e. interface reaction control). ${ }^{42}$ Bosze and Trivedi ${ }^{98}$ subsequently reanalysed the Heckel-Paxton data ${ }^{42}$ using a somewhat modified approach to that employed earlier for proeutectoid ferrite, ${ }^{99}$ which was itself based on a model originally developed by Trivedi, ${ }^{100,101}$ in which interfacial structure effects were taken into account indirectly through an interface kinetics coefficient, $\mu_{\mathrm{o}}{ }^{100-102}$ They ${ }^{98}$ incorporated both isotropic and anisotropic interface kinetics coefficients, and showed that even if the isotropic kinetics coefficient was chosen to fit the Heckel-Paxton experimental data at the highest isothermal temperature studied for each alloy, the calculated lengthening rates for all other temperatures were about an order of magnitude lower than the experimental observations. Alternatively, the anisotropic model could be brought into reasonable agreement with the experimental data if appropriate values of the interface kinetics coefficient, $\mu_{\mathrm{o}}$, and the anisotropy parameter, $a_{1}$, were chosen (i.e. fitted to the data), particularly if $\mu_{\mathrm{o}}$ was allowed to decrease with decreasing temperature. However, a more direct comparison between calculated and experimental values, in which these two parameters were not adjusted empirically, could not be made, ${ }^{98}$ and independently determined values of $\mu_{\mathrm{o}}$ and $a_{1}$ are not available. ${ }^{95}$ Although more direct calculations based on interface migration by the ledge mechanism have demonstrated that ledged interfaces can exhibit migration kinetics well below those predicted for ledge free disordered boundaries, ${ }^{103,104}$ lack of data on ledge heights and ledge spacings at the edges of Widmanstätten cementite plates prohibit such direct modelling of cementite plate lengthening. Additionally, it is difficult to separate out the effects of $\mathrm{Si}$ on the Heckel-Paxton data, as their alloys contained about $0.25 \% \mathrm{Si}$, and it has been suggested that $\mathrm{Si}$ can strongly inhibit cementite growth ${ }^{42}$ due to its reported low solubility in cementite. ${ }^{105}$ As far as the present authors are aware, no other detailed growth kinetics measurements have been reported for Widmanstätten proeutectoid cementite.

\section{Grain boundary cementite}

Heckel and Paxton also measured the thickening kinetics of grain boundary allotriomorphic films of proeutectoid cementite in the three plain carbon steels mentioned above, as well as in a high purity $\mathrm{Fe}-1 \cdot 16 \% \mathrm{C}$ alloy, ${ }^{42}$ while Ando and Kraus preformed growth measurements on similar grain boundary proeutectoid cementite films in a commercial AISI 52100 steel, ${ }^{10}$ and in a high purity $\mathrm{Fe}-1 \cdot 06 \mathrm{C}-2 \cdot 26 \mathrm{Cr}-0 \cdot 03 \mathrm{Si}$ alloy. ${ }^{66}$ It has been pointed out ${ }^{95}$ that all of these studies reported essentially the same overall behaviour, i.e. that the measured thickening rates of grain boundary cementite films become very sluggish at relatively long isothermal reaction times, falling well below those calculated based on volume-diffusion controlled migration of ledge free cementite/austenite interfaces, and that thickening often stops long before the expected equilibrium fraction of cementite is formed ${ }^{10,42,66}$ (see Fig. 13). The reasons proposed by these sets of authors for the sluggish growth included silicon build-up in austenite at the cementite/austenite interface, ${ }^{10,42}$ and chromium partitioning between austenite and cementite. ${ }^{10,66}$ Ando and Krauss also recognised that the interfacial ledges they observed ${ }^{10}$ most likely played a role in controlling the thickening kinetics, and thus applied a Jones-Trivedi ledge growth analysis to show that the sluggish growth kinetics data in their high purity $\mathrm{Fe}-\mathrm{C}-\mathrm{Cr}-\mathrm{Si}$ alloy were consistent with an increase in average interledge spacing with time, but ledge spacings (and heights) were not determined experimentally as a function of time to directly verify this deduction. ${ }^{66}$ Such effects of interfacial ledges could likewise be at least partially responsible for the sluggish growth kinetics observed by Heckel and Paxton ${ }^{42}$ as well.

In their investigation of the effects of $\mathrm{Cu}$ on proeutectoid cementite precipitation in $\mathrm{Fe}-1.43 \mathrm{C}$ and 

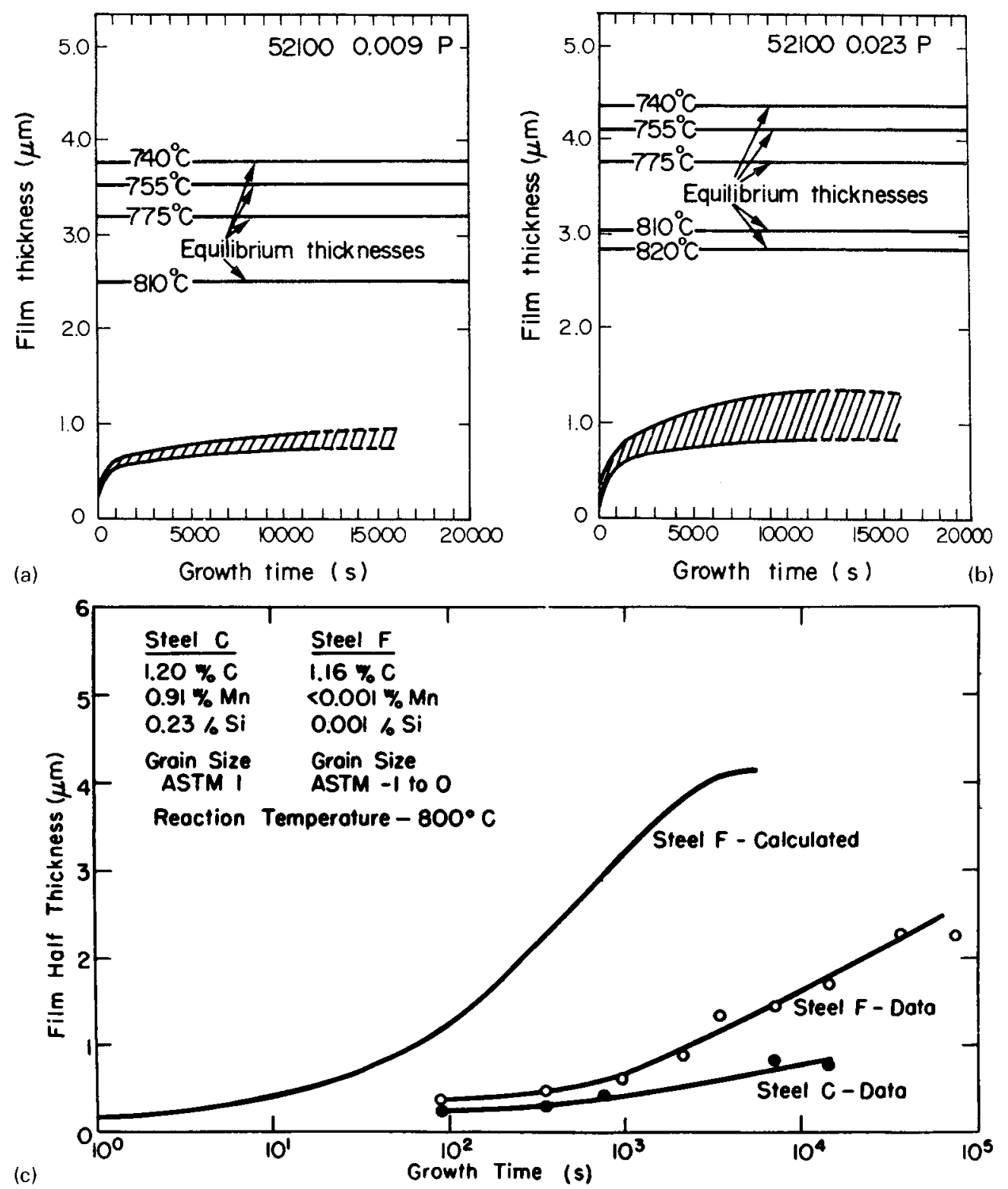

13 Measured proeutectoid cementite film thickness as function of growth time and calculated equilibrium film thickness for two AISI 52100 steels of $a 0.009 \% \mathrm{P}$ and $b$ 0.023\% (taken from Ando et al. ${ }^{10}$ ); $c$ calculated and experimentally measured half thickness of cementite films in an Fe-1.16C high purity steel (steel F) reacted at $800^{\circ} \mathrm{C}$ with experimental data from a $1.20 \% \mathrm{C}$ plain carbon steel (steel C) shown for comparison (taken from Heckel et al. ${ }^{42}$ )

$\mathrm{Fe}-1 \cdot 49 \mathrm{C}-4 \cdot 90 \mathrm{Cu}$ alloys, Wasynczuk et al. ${ }^{67}$ reported that $\mathrm{Cu}$ had a negligible influence on the overall transformation kinetics (TTT curves) of proeutectoid cementite, but that in general, proeutectoid cementite grain boundary allotriomorphic films thicken at rates considerably less than those allowed by the diffusion of carbon through austenite. This is in agreement with the results of the earlier investigations just mentioned. ${ }^{10,42,66}$ As mentioned earlier in the discussion of the interfacial structure (in the above section on 'Habit plane, growth direction and interfacial structure of proeutectoid cementite precipitates'), based on both kinetic and structural observations, they ${ }^{67}$ also deduced that the copper particles precipitated at partially coherent facets at the cementite/austenite interfaces, similar to interphase precipitation at other ledged interfaces. ${ }^{91-94}$ These findings ${ }^{67}$ are consistent with the earlier observations of Ando and Krauss of ledges at grain boundary cementite/ austenite interfaces in $1 \mathrm{C}-1 \cdot 5 \mathrm{Cr}$ steels, ${ }^{10}$ as well as with the suggestion that such ledges can contribute to the sluggish grain boundary cementite growth kinetics. ${ }^{66}$

In a subsequent analysis of the growth kinetics data of Heckel and Paxton ${ }^{42}$ and Ando and Krauss, ${ }^{10,66}$ Spanos et $a l .{ }^{95}$ recognised that only for the data corresponding to the high purity $\mathrm{Fe}-1 \cdot 16 \mathrm{C}$ alloy studied by Heckel and Paxton could potential alloying element effects due to $\mathrm{Si}$ and/or $\mathrm{Cr}$ be ruled out. It was also recognised though that even in this alloy the sluggish growth kinetics might not solely be attributed to interfacial structure effects associated with ledges, since the previous theoretical analysis $^{42}$ employed semi-infinite boundary conditions for the carbon diffusion field in austenite, and thus had not considered possible effects of soft impingement of carbon diffusion fields within austenite grains of finite size. The latter investigators ${ }^{95}$ thus performed calculations to examine the validity of this assumption in the $\mathrm{Fe}-1 \cdot 16 \mathrm{C}$ alloy by employing a growth model which explicitly accounted for soft impingement effects, but 
was still based on the migration of ledge free disordered cementite/austenite interphase boundaries. These calculations showed that although some diffusion field overlap was predicted at very late transformation times, the experimental cementite film thickening times ${ }^{42}$ were still greater by more than an order of magnitude than those calculated. ${ }^{95}$ Thus, soft impingement of carbon diffusion fields was ruled out ${ }^{95}$ as an explanation for the sluggish growth kinetics in the high purity $\mathrm{Fe}-1 \cdot 16 \mathrm{C}$ alloy studied by Heckel and Paxton. ${ }^{42}$

It was therefore reasoned ${ }^{95}$ that since all other possibilities had been ruled out, the remaining explanation for the large discrepancy between theoretical and experimental grain boundary cementite film thickening rates in the $\mathrm{Fe}-1 \cdot 16 \mathrm{C}$ alloy appeared to be an interfacial structure barrier to growth, consistent with observations of ledges at similar grain boundary cementite interfaces in other alloys. ${ }^{10,56}$ In particular, it was suggested, based on prior theoretical analyses of growth by the ledge mechanism, that the overall boundary migration rate would be sluggish if the ratio of the ledge height to spacing, $h / \lambda$, became small. ${ }^{95}$ Employing the ledge growth model of Atkinson, ${ }^{106}$ and the limited experimental data on values of interledge spacing $(\lambda)$ and ledge height $(h)$ published at that time for proeutectoid cementite, ${ }^{10,49}$ the values of interledge spacing which would yield the experimental cementite film thicknesses observed by Heckel and Paxton in the $\mathrm{Fe}-1 \cdot 16 \mathrm{C}$ alloy were back calculated as a function of time (in these calculations, the initial value of $\lambda$ was based on published SEM micrographs of Ando and Krauss ${ }^{10}$ ) (see Table 2). The calculations suggested that the sluggish thickening and eventual growth stasis observed experimentally for proeutectoid cementite grain boundary films in the $\mathrm{Fe}-1 \cdot 16 \mathrm{C}$ alloy ${ }^{42}$ could be attributed to a drastic decrease and eventual cessation of ledge production - or alternatively, a drastic increase in interledge spacing - at late reaction times. ${ }^{95}$ It was also pointed out $^{95}$ that similar increases in interledge spacing with time had been experimentally observed for other precipitation reactions during plate thickening ${ }^{107,108}$ and plate coarsening, ${ }^{109,110}$ including the absence of growth ledges at long reaction times being shown to result in the complete cessation of plate thickening in Al-15Ag. ${ }^{108}$ Along these lines, Ando and Kraus performed somewhat similar ledge growth calculations to suggest that an increase in interledge spacing with time could also be at least partially responsible for the observed sluggish cementite grain boundary film growth kinetics observed in their $\mathrm{Fe}-1 \cdot 06 \mathrm{C}-2 \cdot 26 \mathrm{Cr}-0 \cdot 03 \mathrm{Si}$ alloy. $^{66}$

\section{Formation mechanism(s) of proeutectoid cementite}

The last section of this paper will now summarise, build upon and integrate the foundation of detailed results reviewed and discussed in detail above, in order to provide a final, comprehensive, modern view of the formation mechanism(s) of proeutectoid cementite. This section will also consider in more detail the nucleation site of proeutectoid cementite in the austenite. Consideration will first be given to Widmanstätten proeutectoid cementite, and then to grain boundary proeutectoid cementite (i.e. cementite which forms along austenite grain boundaries and does not grow appreciably, other than some thickening, into the interior of the austenite grains).

\section{Formation mechanism(s) of Widmanstätten proeutectoid cementite}

Morphology and sympathetic nucleation of Widmanstätten cementite

Three-dimensional morphological studies have demonstrated that Widmanstätten cementite typically takes on one of two morphologies:

(i) single crystal monolithic plates sometimes stacked atop one another in a face to face arrangement (Fig. 6)

(ii) aggregates of many fine laths typically stacked in an edge to edge fashion (Fig. 7).

It is believed that the sympathetic nucleation of small cementite crystals atop one another contributes to the formation of such aggregates, and it appears that sympathetic nucleation is more prevalent in the case of the fine cementite laths (as opposed to monolithic cementite plates). At the optical level of resolution, the external morphology of such sympathetically nucleated aggregates, even in $3 \mathrm{D}$, can exhibit a continuous range of shapes with a widely varying range of length/width aspect ratios, and with $2 \mathrm{D}$ observation techniques alone, the morphology can be misinterpreted.

\section{Original nucleation site(s) of Widmanstätten proeutectoid cementite in the austenite matrix}

Serial sectioning and $3 \mathrm{D}$ reconstruction studies have shown, at least in some hypereutectoid steels, that the original nucleation site of Widmanstätten cementite within the austenite grains is always either at austenite grain boundaries, or in association with (i.e. either on top of or directly adjacent to) grain boundary proeutectoid cementite that has already formed and grown along the austenite grain boundaries. ${ }^{16,19,90}$ That is, no intragranular Widmanstätten cementite was observed in $3 \mathrm{D}$ (e.g. for all of the more than 200 precipitates fully reconstructed in one $3 \mathrm{D}$ study ${ }^{16}$ ), despite the fact that many of the precipitates reconstructed and shown in 3D to connect to grain boundaries would certainly have been classified as intragranular, if the classification had been based only on individual 2D observations/ micrographs from a single plane of polish. ${ }^{16}$ Additionally, in terms of the Dubé morphological classification system, ${ }^{1,33,34}$ the majority of Widmanstätten plates and laths observed in these studies ${ }^{16,19,90}$ appear to be

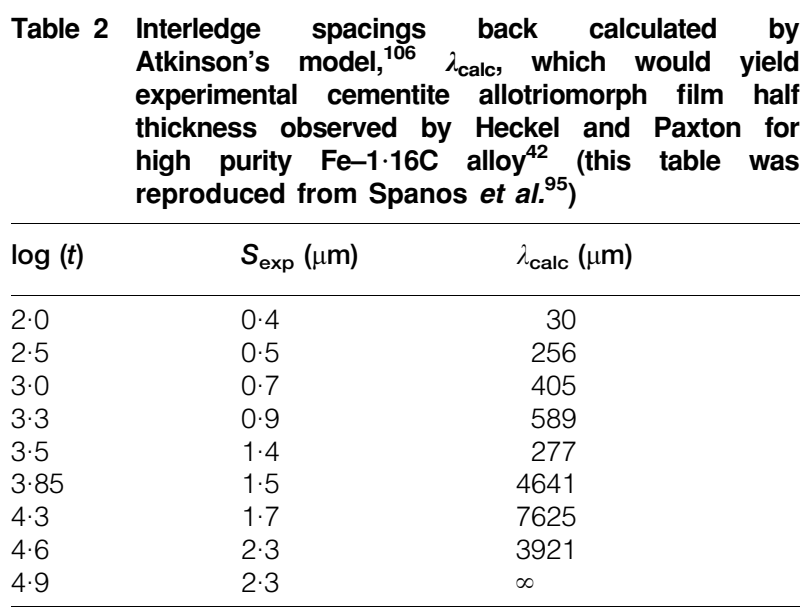


secondary sideplates (or laths), as opposed to primary sideplates (or laths) nucleated at cementite free austenite grain boundaries (see Fig. 3b). Based on the clear similarities between 2D cementite morphologies as shown in the $2 \mathrm{D}$ micrographs of a number of earlier studies, ${ }^{12,15,18,21,41,47,49,53,55-58}$ and the 2D morphologies from micrographs corresponding to individual sections in the 3D investigations, ${ }^{13,16,17,19,90,111}$ it is believed that the phenomenon of little or no intragranular precipitation of Widmanstätten proeutectoid cementite in 3D could be widely applicable to other hypereutectoid steels as well (at least those which also have relatively low inclusion densities, since inclusions can act as nucleation sites). More 3D studies in a wide variety of hypereutectoid alloys would be needed though to definitively verify this deduction.

As discussed in detail in the section on orientation relationships (ORs) above, although a number of proeutectoid cementite/austenite ORs have been reported in the literature (see Table 1), it has become clear that Widmanstätten cementite which possesses a $3 \mathrm{D}$ monolithic plate morphology obeys the Pitch OR, ${ }^{22,23}$ while $3 \mathrm{D}$ lath aggregates obey the Farooque-Edmonds (F-E) OR. ${ }^{21}$ The question arises as to how this correspondence between the OR and 3D morphology is established during the formation of Widmanstätten proeutectoid cementite. Since the OR is dictated at the nucleation stage, the OR of the Widmanstätten cementite is apparently chosen to minimise the energy of the critical nucleus at the site in austenite upon which nucleation occurs, which has been shown in $3 \mathrm{D}$ to be austenite grain boundaries, or more likely by sympathetic nucleation atop of grain boundary proeutectoid cementite that has already formed and is growing along the austenite grain boundaries. ${ }^{16,19,90}$ The most definite identification of a nucleation site in three dimensions was shown by Kral and Fonda (see Figure 5 of Ref. 90), where Widmanstätten laths at relatively early stages of formation were shown to emanate from points of impingement of the grain boundary cementite crystals comprising the cementite film. ${ }^{90}$ Nucleation and growth of the cementite laths was thus shown to occur with very small (or no) misorientations upon grain boundary cementite that obtains a near F-E OR with the austenite grain into which growth occurs. In the case of Widmanstätten plates, however, the positive identification of the nucleation site is often defied by impingement of the long plates with multiple sites on the austenite grain boundaries and/or grain boundary cementite. It does seem likely, though, that a similar mechanism may be applicable in the case of the nucleation site of Widmanstätten cementite plates as that which was determined for laths. In other words, Widmanstätten cementite plates (which are known to possess the Pitsch OR with respect to the austenite matrix ${ }^{17,22}$ ) may sympathetically nucleate on grain boundary cementite which approximates the Pitsch OR with respect to one of the austenite grains. Further 3D observations in combination with crystallographic analysis on cementite plates formed at very early stages of transformation (to avoid multiple impingements) would be required to verify this hypothesis.

In attempting to elucidate further the relationship between the OR, the morphology, and the nucleation site and the formation mechanism of Widmanstätten proeutectoid cementite, it will be useful now to consider observed trends in the OR and morphology associated with formation temperature.

It was reported in a study of 3D morphology and crystallography in a $1 \cdot 3 \mathrm{C}-13 \mathrm{Mn}$ alloy that $3 \mathrm{D}$ lath aggregates obeying the $\mathrm{F}-\mathrm{E}$ OR were more prevalent at higher isothermal transformation temperatures than monolithic cementite plates obeying the Pitsch OR, while monolithic cementite plates were more prevalent at the lower transformation temperature studied. ${ }^{17}$ This might be related to a change with temperature in either: (i) the driving force for cementite precipitation, or (ii) the relative lattice parameters and concomitant atomic fit between the austenite and cementite lattices [or to some combination of (i) and (ii)], but sufficient evidence is not currently available to specifically verify or rule out these potential causes. Along these same lines, in an earlier study reporting cementite laths in a lower carbon $(0 \cdot 8 \% \mathrm{C})$ high Mn steel, ${ }^{53}$ it was noted that in a different investigation in lower $\mathrm{Mn}$ steels reacting at higher temperatures, cementite plate morphologies were reported; ${ }^{42}$ it was thus suggested that the difference between lath and plate formation might have to do with either temperature or composition. ${ }^{53}$ But in this case the laths in the one study $^{53}$ were formed at a lower temperature than the plates in the earlier study. ${ }^{42}$ This effect with temperature appears to be opposite that reported in the $3 \mathrm{D}$ investigation in a $1 \cdot 3 \mathrm{C}-13 \mathrm{Mn}$ alloy, ${ }^{17}$ which showed lath aggregates to be more prevalent than monolithic cementite plates at a higher isothermal transformation temperature. This difference in trends with temperature is likely to be due to the fact that in the assessment of temperature effects between the other two studies ${ }^{42,53}$ complications were introduced because different alloy compositions were considered in each study, as was properly pointed out; ${ }^{53}$ whereas, temperature effects were compared in a single alloy in the $3 \mathrm{D}$ study. ${ }^{17}$

\section{Growth of proeutectoid Widmanstätten cementite}

After nucleation, the full 3D Widmanstätten morphology then develops during growth, such that the F-E (or $\mathrm{Z}-\mathrm{S}$ ) OR facilitates the formation of lath aggregates, while the Pitsch OR results in the establishment of monolithic plates. This is likely related to the fact that the Pitsch OR accommodates not only a direction of very good fit between the cementite and austenite lattices, $[110]_{\mathrm{A}} / /[010]_{\mathrm{C}}$, but also a set of conjugate atomic habit planes of very good fit, resulting in a unique atomic habit plane of $(1 \overline{1} 3)_{\mathrm{A}} / /(101)_{\mathrm{C}}{ }^{49,58}$ Alternatively, it has been shown by modelling studies that the F-E OR possesses one good fit direction, $[112]_{\mathrm{A}} / /[100]_{\mathrm{C}},{ }^{15,87}$ which is also the primary direction of lath growth (i.e. the long axis of the laths). ${ }^{87,90}$ However, a unique, good fit habit plane for the F-E OR (as occurs in the case of the Pitsch OR for plates) has not been established by either modelling or experimental observations. ${ }^{87}$ It has been shown experimentally that the lath habit plane is less regular, as compared to plates, and typically varies by about $10-15^{\circ}$ about the $(001)_{\mathrm{C}}{ }^{87,90}$

At the atomic level, this difference in the evolution of the two Widmanstätten morphologies could likely be related to the ability to form interfacial growth ledges and kinks at various boundary orientations, i.e. due to the anisotropy of ledge and kink formation. ${ }^{77}$ Specifically, these observations for Widmanstätten 
cementite would be consistent with the formation and migration of interfacial growth ledges and kinks quite easily at a large number of boundary orientations in the case of laths. Alternatively, in the case of plates, ledge and kink formation would occur readily at the plate edges only. Another school of thought suggests that structural and analytical observations on Widmanstätten proeutectoid cementite formation are 'not inconsistent with a displacive mechanism' of transformation ${ }^{18,55,56}$ (analogous to martensite formation). This line of reasoning will be discussed in more detail later, after further details of the effects of habit planes and interfacial structure on interface migration are considered.

During the growth stage of Widmanstätten cementite possessing the Pitsch OR, plates develop with a well established atomic habit plane, $(1 \overline{1} 3)_{\mathrm{A}} / /(101)_{\mathrm{C}}$, corresponding to the terraces of interfacial ledges, ${ }^{4,58}$ while the average plate habit plane viewed with conventional TEM can vary significantly (by as much as about $10^{\circ}$ ) from this atomic habit plane due to the presence of both fine and coarse ledges (see Fig. 10a), and the apparent habit plane viewed by optical microscopy can differ even more due to the effects of sympathetic nucleation (Fig. 10b). This observed atomic habit plane has been confirmed by various types of modelling studies to be the conjugate planar pair of best fit between the austenite and cementite lattices obeying the Pitsch OR. ${ }^{15,49,70,82,87}$ As has been discussed in general for solid state transformations, such interfaces of good atomic fit should result in lower ledge nucleation kinetics and thus lower boundary mobilities, allowing these interfaces to develop into relatively broad expanses (i.e. with large interfacial area). In comparison, highly ledged and kinked plate edges should have greater mobility. ${ }^{77}$ Lack of quantitative data on ledge spacings and heights at cementite plate edges currently inhibits direct verification of this hypothesis.

Considering the effects of interfacial structure on plate growth, the coarse, curved (kinked) ledges at the broad faces of proeutectoid cementite plates have been suggested to be growth ledges, while the fine ledges with a $[110]_{\mathrm{S}} / /[010]_{\mathrm{C}}$ line direction ${ }^{49,58}$ and a $0 \cdot 38 \mathrm{~nm}$ ledge height $^{58}$ were noted to have similarities to 'direction steps' observed on pearlite/austenite interfaces, ${ }^{78}$ and to have both similarities and differences with structural ledges observed at ferrite/austenite ${ }^{79-81}$ interfaces. ${ }^{49}$ Considering first the role of the fine ledges at the broad faces of cementite plates in the plate thickening, it is difficult based on conventional TEM observations ${ }^{49}$ to assess whether they are immobile structural ledges ${ }^{79-81}$ or can serve as mobile growth ledges or transformation disconnections, the latter of which have both ledge and dislocation character. ${ }^{112}$ Nevertheless, high resolution TEM has shown ${ }^{58}$ that each ledge riser has two edge dislocations associated with it, and these dislocations would have to climb for the fine ledges to move, thus making them nearly immobile from the standpoint of plate thickening, in agreement with $3 \mathrm{D}$ observations which suggest the thickening of these plates is very sluggish. ${ }^{16}$ On the other hand, the coarser curved ledges with larger heights may serve as growth ledges which accommodate some plate thickening, but this has yet to be verified in situ. As mentioned briefly above, other researchers ${ }^{55,56}$ observed similar coarse defects on the broad faces of cementite plates in other hypereutectoid steels, but interpreted them quite differently, suggesting they were extrinsic features resulting from the intersection of stacking faults in the austenite with the cementite plates, ${ }^{55,56}$ and in at least the copper containing hypereutectoid steels they studied suggested it was unlikely that these coarse linear defects could act as growth ledges, due to the observation of precipitation of copper particles on such features. ${ }^{56}$ The subsequent high resolution TEM study in a high $\mathrm{Mn}$ hypereutectoid steel $^{58}$ showed that the interfacial ledges at the broad faces of proeutectoid cementite plates were intrinsic features of the interface that in most cases were not associated with intersections of faults or other defects with the austenite/cementite interface; but this study also reported that in some cases stacking faults were found to emanate from the ledges into the austenite matrix, rather than the intersection of the stacking faults with the austenite/cementite interface causing the ledges. ${ }^{58}$ Apparent differences in interpretation of the formation and function during the cementite growth of these linear defects between the different sets of investigators (Refs. 18, 55 and 56 versus Refs. 12 and 49) might also be related to differences in alloy composition or transformation temperatures.

Concerning plate lengthening, as mentioned above, kinetics studies ${ }^{42}$ reported experimentally observed lengthening rates that were consistently several orders of magnitude below predicted growth rates based on volume-diffusion controlled growth ${ }^{96,97}$ assuming ledge free disordered cementite/austenite interfaces, and this discrepancy was attributed to a combination of silicon effects and non-equilibrium interface conditions. ${ }^{42}$ This data was later reanalysed and the "non-equilibirum interface conditions' were taken into account empirically through use of both isotropic and anisotropic interface kinetics coefficients. ${ }^{98}$ Even though the anisotropic model could be brought into reasonable agreement with the experimental data if appropriate values of the interface kinetics coefficient, $\mu_{\mathrm{o}}$, and the anisotropy parameter, $a_{1}$, were fitted to the data as a function of temperature, more direct comparisons between calculated and experimental values, in which these two parameters were not adjusted empirically, has not been made. In this vein, lack of data on ledge heights and ledge spacings at the edges of Widmanstätten cementite plates have prohibited more direct modelling of cementite plate lengthening based on interface migration by the ledge mechanism.

As mentioned, above, although many researchers have couched Widmanstätten cementite formation as a diffusional transformation, 1,9,11,12,16,42,43,49,58,95,98 another school of thought has suggested that structural and analytical observations on Widmanstätten proeutectoid cementite are 'not inconsistent with a displacive mechanism' of transformation based on the coordinated displacement of the iron atoms coupled with diffusion of carbon $^{18,41,53,56}$ (analogous to martensite formation), as will now be considered in more detail. One of the reasons put forth to suggest a displacive mechanism for Widmanstätten cementite was the lack of Si partitioning in the case of Widmanstätten precipitates, while it was shown that $\mathrm{Si}$ partitioned between the cementite and austenite in the case of the grain boundary nucleated cementite. ${ }^{41}$ Since specific isothermal transformation temperatures were not reported individually for each of 
these transformation products and/or observations, it is difficult to assess the possibility of a transition from equilibrium with alloy partitioning to paraequilibrium (where the substitutional alloying elements do not partition), ${ }^{113-115}$ in a diffusional manner, as has been reported for instance in the case of ferrite ${ }^{116}$ and cementite in tempered martensite. ${ }^{117,118}$ In any case, it was pointed out that the Widmanstätten product in which the Si did not partition was not orthorhombic cementite, but was instead a triclinic carbide phase, ${ }^{41}$ so this result apparently does not apply to Widmanstätten cementite. A similar triclinic phase formed in hypereutectoid steels containing $2 \% \mathrm{Si}$ is suggested in another study to have formed in a displacive manner, i.e. by a shear mechanism. ${ }^{119}$

In the same investigation, ${ }^{41}$ it was pointed out that the Widmanstätten precipitates contained a high density of unidirectional faults, and this was interpreted as suggestive of a displacive transformation. The published micrographs suggest a significantly higher density of faults for the triclinic phase than in the Widmanstätten cementite formed in the $\mathrm{Si}$ free steel. The faults shown in the Widmanstätten cementite ${ }^{41}$ are similar to those shown for Widmanstätten cementite by other researchers, ${ }^{12,19,49,87}$ and have been attributed by the latter authors to be either cementite/cementite boundaries resulting from sympathetic nucleation, ${ }^{12}$ or growth faults, ${ }^{87}$ without invoking a displacive mechanism. Similarly, in the study that suggested the results are not inconsistent with a displacive mechanism, ${ }^{41}$ the authors also stated that the faults observed in cementite plates were often associated with perturbations or large steps at the interface, and thus may be associated with the segmented or subunit nature of some plates, but did not specifically mention sympathetic nucleation. ${ }^{41}$

In a study of Widmanstätten proeutectoid cementite formation in $\mathrm{Cu}$ containing hypereutectoid alloys, ${ }^{56}$ it was suggested that the presence of a midrib free of $\mathrm{Cu}$ precipitates was indicative of a transition in the growth behaviour of the plate, and a displacive mechanism, in parallel with the mechanism of carbide precipitation and observation of a midrib in lower bainite. It is noted here that a purely diffusional mechanism of lower bainite in which the midrib is simply an initial Widmanstätten ferrite plate has been reported by some authors. ${ }^{120-122}$ In the same $\mathrm{Cu}$ containing steels, it was reported that observations of $\mathrm{Cu}$ precipitated on 'coarsely spaced linear defects' at the broad faces of Widmanstätten precipitates suggested that these features were stationary, rather than growth ledges. ${ }^{55,56}$ Based on the published micrograph (Fig. 21 of Ref. 56) it is difficult to determine if the $\mathrm{Cu}$ precipitates nucleated on the ledge risers, or on terraces between ledge risers which subsequently migrated, or on portions of the ledge risers between mobile kinks upon the risers. ${ }^{77}$

It has also been reported that Widmanstätten cementite that grew through mechanically deformed austenite possessed a perturbed structure, similar to bainitic plates reported by others, ${ }^{123}$ and that it appeared that in such cases planar defects in the austenite were occasionally trapped within the cementite, while such effects were not present in the case of pearlite. ${ }^{55}$ In that same investigation a 'regularly spaced fine set of fringes indicating an intrinsic dislocation structure' with a spacing of 3-8 $\mathrm{nm}$ was observed at the broad face of the Widmanstätten cementite, and it was suggested that similar interfacial features have also been reported for lath and plate martensite by Sandvik and Wayman. ${ }^{124,125}$ It now appears quite likely that these 'linear features' correspond to the 'fine ledges' reported by other researchers using both conventional and high resolution $\mathrm{TEM}^{49,58}$ to have regular spacings between 4 and $6 \mathrm{~nm}$, a reproducible line direction of $[110]_{\mathrm{A}} / /[010]_{\mathrm{C}}$, ledge heights of $0.38 \mathrm{~nm}$, a ledge terrace plane of $(1 \overline{1} 3)_{\mathrm{A}} / /(101)_{\mathrm{C}}$, a ledge riser plane of $(\overline{1} 13)_{\mathrm{A}} / /(001)_{\mathrm{C}}$, and two edge dislocations associated with each of these fine ledges. It has been shown that the two edge dislocations are in a sessile orientation with respect to advancement of the austenite cementite interface, such that one or both of the dislocations would have to climb (by a diffusional process) for the interface to migrate. In other words, the interfacial structure is of the sessile type, as opposed to an interface containing glissile dislocations which can advance the interface by glide, as in the case of a martensite transformation. ${ }^{77,125}$ Additionally, the general presence of an 'intrinsic dislocation structure' at an interphase interface does not in and of itself appear to preclude either a displacive or a diffusional mechanism, unless it is determined whether the dislocations at the interface correspond to either glissile structures typical of displacive transformations, ${ }^{125}$ or sessile structures typical of diffusional transformations. ${ }^{77,80,81}$

Significantly fewer observations have been reported for the interfacial structure of proeutectoid cementite laths. It is suggested here that this might have been due at least in part to the fact that when viewed on $2 \mathrm{D}$ planes of polish the lath conglomerates observed in $3 \mathrm{D}^{16,17,19,20}$ are likely to have been mistaken for plates, at least in some cases, by researchers in the past. $1,7,11,12,14,15,18,21,23,25,41-43,47-50,54-58$ As alluded to earlier in the current review article, this idea is supported by the fact that in some of the detailed 3D studies, a number of the precipitates that appeared to be plates in individual 2D cross-sections (and typically would have been classified as such based on their 2D appearance) were shown to be lath aggregates when observed in 3D. ${ }^{16,17,19,20}$

Nevertheless, it has been shown that the individual proeutectoid cementite laths possess a $[100]_{C}$ lath growth direction (lath long axis), and the broad face, or habit plane of the laths varies from 10 to $15^{\circ}$ from the $(001)_{\mathrm{C}}$ plane orientation. ${ }^{87,90}$ The broad faces of the cementite laths were shown to contain a complex interfacial structure consisting of three types of features:

(i) direction steps

(ii) another set of misfit compensating defects described as either misfit dislocations or structural ledges

(iii) a coarser set of curved features which were interpreted as either growth ledges or intruder dislocations. $^{87}$

As far as the present authors are aware, no quantitative experimental studies (or calculations) specific to proeutectoid cementite lath thickening, widening, or lengthening have been reported, in order to more quantitatively elucidate the mechanism of lath growth, and thus relate the observed lengthening direction and interfacial structure of the laths to their growth.

It has also been shown that in 3D both Widmanstätten proeutectoid cementite plates and laths 
can intersect and appear to go through/around one another during the growth process ${ }^{13,14,16,17}$ (e.g. see Fig. $6 d$ ). More specifically, the morphologies in these 3D studies appear to result from Widmanstätten cementite precipitates growing into contact and filling in around other Widmanstätten cementite precipitates that have already formed, with the final appearance (particularly when viewed on a 2D plane of polish) being that of precipitates that 'intersect' one another at large angles.

\section{Formation mechanism(s) of grain boundary proeutectoid cementite}

\section{Morphology of grain boundary proeutectoid cementite}

As considered in detail earlier, a series of 3D studies in an $\mathrm{Fe}-1 \cdot 3 \mathrm{C}-13 \mathrm{Mn}$ alloy ${ }^{13,16,19,20,126}$ revealed that grain boundary proeutectoid cementite allotriomorphs possess a fernlike or dendritic morphology in $3 \mathrm{D}$, in which the cementite dendrite arms grow predominantly in the austenite grain boundary planes, but do not extend significantly into the interior of the austenite grains, other than by some amount of thickening, and then very rapidly impinge along the austenite boundaries to form a continuous film of cementite (see Fig. 8). This is clearly in contrast to a 'bulged pancake"1 or double spherical cap $^{63,64}$ type of 'allotriomorph' typically deduced from the past investigations of grain boundary cementite that were centred about 2D observations only (e.g. Refs. 1, $11,42,56$ and 67). Owing to the almost identical appearance in 2D of the grain boundary cementite observed in both the $3 \mathrm{D}^{13,16,19,20}$ and the $2 \mathrm{D}^{10,11,42,65,67}$ studies, and examples of the correlation between $2 \mathrm{D}$ and $3 \mathrm{D}$ observations in a single specimen in the $3 \mathrm{D}$ studies, ${ }^{13,16,19,20}$ it is highly likely that the grain boundary cementite in many (if not all) of the essentially 2D studies ${ }^{10,11,42,65,67}$ possessed a dendritic morphology as well.

\section{Nucleation of grain boundary proeutectoid cementite}

By combining the results of $3 \mathrm{D}$ studies at very early transformation times ${ }^{126}$ with those at longer transformation times ${ }^{16,20}$ in a single hypereutectoid high $\mathrm{Mn}$ alloy, a new picture of the nucleation and subsequent growth of grain boundary cementite in austenite has emerged. Experimental observations suggest that solid state grain boundary cementite dendrites do not nucleate at grain boundaries in $3 \mathrm{D},{ }^{126}$ but instead nucleate at austenite grain corners and edges, and then rapidly grow along the grain edges and then along the grain boundaries ${ }^{16,20,126,127}$ (see Fig. 14). This type of nucleation sequence is not unexpected, based on energy considerations of heterogeneous nucleation at grain corners, edges and boundaries, ${ }^{128}$ but was not previously elucidated experimentally in $3 \mathrm{D}$.

The fact that heterogeneous nucleation at grain corners, edges and boundaries should occur in such a way as to minimise the energy of the critical nucleus ${ }^{128,129}$ is consistent with experimental results of an EBSD study of the orientation relationship of 194 grain boundary proeutectoid cementite dendritic precipitates in an $\mathrm{Fe}-1 \cdot 34 \mathrm{C}-13 \mathrm{Mn}$ alloy. ${ }^{20}$ In that study, roughly $75 \%$ of the grain boundary cementite precipitates were shown to exhibit one of the known orientation relationships, with respect to at least one of the adjacent austenite grains. Such orientation relationships are obtained during nucleation in order to allow good fit between the lattices, and thus minimise the energy of the (a)

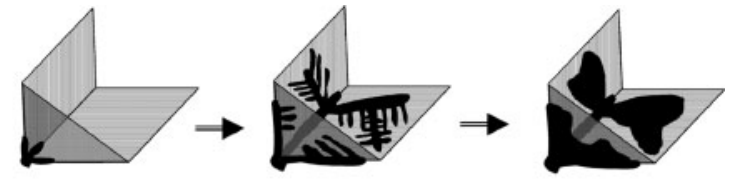

(b)

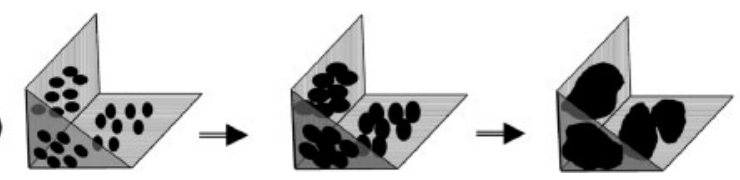

14 Schematic representations of grain boundary cementite formation by a new corner/edge nucleated dendritic model, and $b$ previous models of allotriomorph formation on grain faces: grey planes represent austenite grain boundaries and black represents proeutectoid cementite (reproduced from Spanos et al. ${ }^{127}$ )

critical nucleus. For the roughly $25 \%$ of grain boundary cementite precipitates that deviated by more than $10^{\circ}$ from any of the known orientation relationships with either adjacent grain (viewed in 2D), it was suggested that this may have been due to the fact that those precipitates nucleated at grain edges or grain corners not apparent in the 2D plane of polish from which the EBSD analysis was performed, and more specifically, that the austenite grains corresponding to the grain boundaries observed on the 2D plane of polish may have been different from the one(s) dictating the OR at the original nucleation site in $3 \mathrm{D} .^{20}$ This is quite consistent with the other 3D findings just mentioned - that solid state grain boundary cementite dendrites do not nucleate at grain boundaries, ${ }^{126}$ but instead nucleate at austenite grain corners and edges, followed by rapid growth along the grain edges, and then along the grain boundaries (Fig. 14). ${ }^{16,20,126,127}$

\section{Growth of grain boundary proeutectoid cementite}

During the growth of these grain boundary dendrites, it was found that the primary arm growth direction is not unique, and this was attributed, at least in part, to the fact that the crystallographic constraints on cementite growth are relaxed within the more open structure of the austenite grain boundaries, thus helping to allow the solid date dendrites to form in the first place. ${ }^{20}$ On a finer level this was suggested most likely to be due to the relative ease of growth ledge and kink formation along cementite/austenite interfaces. ${ }^{20}$ In this regard, grain boundary allotriomorphic cementite, now determined to have a dendritic morphology in three dimensions, ${ }^{13,16,19,20}$ has been shown in various hypereutectoid steels to contain growth ledges (and kinks) at the cementite/austenite interface. ${ }^{10,56}$

These solid state grain boundary dendrites quickly impinge to form continuous cementite films along the austenite grain boundaries. ${ }^{13,16,19,20}$ Independent quantitative studies of the thickening kinetics of such proeutectoid cementite grain boundary films in various hypereutectoid steels ${ }^{10,42,66}$ have been made, and all reported essentially the same overall findings that the measured thickening rates of grain boundary cementite films become very sluggish at relatively long isothermal reaction times, falling well below those calculated based on volume-diffusion controlled migration of ledge free cementite/austenite interfaces, and that thickening often stops long before the expected equilibrium fraction of 
cementite is formed $^{10,42,66}$ (see Fig. 13). Proposed reasons for the sluggish growth include silicon buildup in austenite at the cementite/austenite interface, ${ }^{10,42}$ chromium partitioning between austenite and cementite, ${ }^{10,66}$ and effects of interfacial ledges. ${ }^{10}$ Subsequently, calculations based on ledge growth models indicated that a drastic decrease and eventual cessation of ledge production (i.e. increase of interledge spacing) at late reaction times could account for the sluggish kinetics. ${ }^{66,95}$

Based in large part on many of the more recent studies discussed above, a new mechanism for the formation of grain boundary cementite is thus presented schematically in Fig. 14, along with a comparison with the previously accepted formation mechanism.

\section{Summary and conclusions}

This paper is the first review specifically focused on all aspects of the proeutectoid cementite transformation, since Professor H. I. Aaronson's chapter in the book entitled 'The Decomposition of Austenite by Diffusion Processes', published in 1962. ${ }^{1}$ Since publication of Professor Aaronson's article in 1962, ${ }^{1}$ the morphological descriptions of proeutectoid cementite originating from 2D observations have been rewritten based on modern 3D analyses. Simultaneously, the 3D analyses in conjunction with crystallographic analysis enabled some of the confusion about the many reported orientation relationships of cementite within austenite to be clarified. In a similar way, recent conventional and atomic resolution electron microscopy studies, along with atomic and crystallographic modelling work, have clarified many of the aspects of nucleation, growth, and habit planes, and thus some of the underlying reasons for certain precipitates adopting various 3D morphologies. Moreover (and this statement may form a methodology for the study of all phases with irregular morphologies that cannot be described simply with 2D observations), the proper 3D description of the possible morphologies provides a solid framework upon which many other aspects of the transformation can be built. Finally, most of these findings and conclusions on proeutectoid cementite, discussed in detail in earlier sections of this paper, have been integrated and summed up in the last major section of this review in order to provide a comprehensive, modern view of the proeutectoid cementite transformation.

It should also be mentioned that this topic of study, the proeutectoid cementite transformation, is one of the few transformation studies that has been carried out over such a long period of time, and thus has seen the advent of new experimental techniques continuously applied to answer many questions about the "what, where, why and how' of solid state phase transformations. It is interesting that even for a phase transformation that has been studied for as long as about 100 years, critical pieces of information to explain various aspects of the transformation are still being collected.

Looking toward the future, it is worth considering what further work is required in order to obtain an even more complete understanding of proeutectoid cementite formation. For example, a full explanation of the evolution of the sawteeth and zig-zag grain boundary cementite morphologies, the atomic habit plane of the F-E OR Widmanstätten laths, and the relationship between the $\mathrm{T}-\mathrm{H}$ and Pitsch ORs remain to be elucidated. Kinetic studies have focused solely on grain boundary cementite thickening and Widmanstätten cementite plate lengthening, so there is a gap in this type of knowledge for Widmanstätten laths. Even though it is very difficult to study experimentally, the nucleation site of Widmanstätten plates needs to be accurately determined. Additionally, detailed in situ studies of proeutectoid cementite formation would provide further details and verification (or refutation) of the findings and deductions made from static observations.

Finally, many of the new findings, concepts, and features presented here for this classic phase transformation in steels, proeutectoid cementite, may also be broadly applicable as a general model from which to consider many other phase transformations in a variety of other alloy systems as well. For example, in Ti alloys, $3 \mathrm{D}$ studies of grain boundary allotriomorph formation could prove useful by way of comparison to the observations for proeutectoid cementite, to test if grain boundary precipitates in some $\mathrm{Ti}$ alloy systems might actually be solid state dendrites, particularly for the different crystal structure change corresponding to formation of an hep precipitate $(\alpha)$ from a bec matrix $(\beta)$ in $\mathrm{Ti}-\mathrm{Cr}$ and other binary alloys. ${ }^{130}$ Similarly, in precipitate reactions such as $\alpha$ formation in $\mathrm{Ti}$ alloy systems, the proeutectoid ferrite transformation in steels, intermetallic compound formation in $\mathrm{Al}-\mathrm{Cu}$ and other $\mathrm{Al}$ alloys, and/or the formation of different alloy carbides in steels (such as $\mathrm{M}_{23} \mathrm{C}_{6}$ ), it would be useful to examine the degree of true intragranular precipitation, as determined directly by $3 \mathrm{D}$ studies, and to determine if correlations exist between the matrix-precipitate orientation relationship and the morphology of Widmanstatten precipitates, as was found for proeutectoid cementite. In these and other such studies in various alloy systems, differences among the different transformations would also need to be considered, such as the nature of the relevant solute, the operative crystallography (orientation relationships), the transformation driving force, and the role of impurities.

\section{Acknowledgements}

G. Spanos gratefully acknowledges support of the Office of Naval Research (ONR) and the Defense Advanced Projects Research Agency (DARPA) through ONR grant \#s N0014-08-WX-2-0726 and N0014-08-WX-20096 (program manager, J. Christodoulou), and the Naval Research Laboratory (NRL) through NRL base funding.

\section{References}

1. H. I. Aaronson: in 'The decomposition of austenite by diffusional processes', (ed. V. F. Zackay and H. I. Aaronson), 387-546; 1962, New York, Interscience.

2. H. C. Sorby: J. Iron Steel Inst., 1887, 30, 255.

3. F. Osmond: Trans. AIME, 1893, 22, 243.

4. H. Howe: Proc. Am. Soc. Test. Mater., 1911, 11, 262

5. O. Forsman: Jern-Kontorets Ann., 1918, 102, 1-30.

6. S. B. Hendricks: Zeitschrift fur Kristallographie, 1930, 74, 534 545.

7. R. F. Mehl, C. S. Barrett and D. W. Smith: Trans. AIME, 1933, 105, 215-258.

8. A. B. Greninger and R. Troiano: Trans. AIME, 1940, 140, 307331 . 
9. G. Spanos and M. V. Kral: in 'Encyclopedia of materials: science and technology', 2nd edn, (ed. K. H. J. Buschow et al.), 7893 7898; 2001, Oxford, Elsevier Science Ltd.

10. T. Ando and G. Krauss: Acta Metall., 1981, 29, 351-363.

11. R. W. Heckel and H. W. Paxton: Trans. ASM, 1961, 53, 539-554.

12. G. Spanos and H. I. Aaronson: Scripta Metall., 1988, 22, 1537 1542 .

13. M. V. Kral and G. Spanos: Scripta Mater., 1997, 36, 875-882.

14. M. A. Mangan, P. D. Lauren and G. J. Shiflet: J. Microsc., 1997, 188, 36-41.

15. M. X. Zhang and P. M. Kelly: Acta Metall., 1998, 46, 4617-4628.

16. M. V. Kral and G. Spanos: Acta Metall., 1999, 47, 711-724.

17. M. A. Mangan, M. V. Kral and G. Spanos: Acta Mater., 1999, 47, $4263-4274$.

18. F. A. Khalid and D. V. Edmonds: Proc. Int. Conf. on 'Solid-solid phase transformations '99 (JIMIC-3), (eds. M. Koiwa et al.), 1493-1496; 1999, Sendai, Japan Institute of Metals.

19. M. V. Kral: Mater. Charact., 2000, 45, 105-110.

20. M. V. Kral and G. Spanos: Acta Mater., 2003, 51, 301-311.

21. M. Farooque and D. V. Edmonds: Proc. 12th Int. Congress for Electron Microscopy, (eds. L. W. Hobbs and R. Sinclair), 910 911; 1990, San Francisco, CA, San Francisco Press.

22. W. Pitsch: Acta Metall., 1962, 10, 897-900.

23. W. Pitsch: Archiv fur das Eisenhuttenwsen, 1963, 34, 381-390.

24. S. W. Thompson and P. R. Howell: Scripta Metall., 1988, 22, 229 233.

25. M.-X. Zhang and P. M. Kelly: Scripta Mater., 1997, 37, $2017-$ 2024.

26. D. S. Zhou and G. J. Shiflet: Scripta Metall., 1992, 27, 1215-1218.

27. E. C. Bain and H. W. Paxton: 'Alloying elements in steel'; 1966, Metals Park, OH, ASM.

28. M. Hillert and M. Waldenstrom: Metall. Trans. A, 1977, 8A, 5 13.

29. D. V. Doane and J. S. Kirkaldy: 'Hardenability concepts with applications to steel'; 1978, Warrendale, PA, TMS-AIME.

30. B. Sundmand, B. Jansson and J. O. Andersson: Calphad, 1985, 9 , 153-190.

31. Thermo-Calc: 'Thermo-Calc Thermodynamics Software', http:// www.thermocalc.com/, 2007.

32. Y. D. Zhang, C. Esling, M. L. Gong, G. Vincent, X. Zhao and L. Zuo: Scripta Mater., 2006, 54, 1897-1900.

33. C. A. Dubé: PhD thesis, Carnegie-Mellon University, Pittsburgh, PA, 1948

34. C. A. Dubé, H. I. Aaronson and R. F. Mehl: Revue de Metallurgie., 1958, 55, 201-210.

35. M. V. Kral and G. Spanos: Metall. Mater. Trans. A, 2005, 36A, 1199-1207.

36. G. Spanos, A. W. Wilson and M. V. Kral: Metall. Mater. Trans. A, 2005, 36A, 1209-1218.

37. Farlex: 'The free dictionary'; 2007, Farlex Inc.

38. C. S. Smith: 'History of metallography: the development of ideas on the structure of metals before 1980', 2nd edn; 1988, MIT Press.

39. R. F. Mehl and C. S. Barrett: Trans. AIME, 1931, 93, 78-122.

40. R. F. Mehl and O. T. Marzke: Trans. AIME, 1931, 93, 123-161.

41. F. A. Khalid, M. Farooque and D. V. Edmonds: Proc. Int. Conf. on 'Martensitic transformations (1992)', (eds. C. M. Wayman and J. Perkins), 431-437; 1993, Carmel, CA, Montery Institute for Advanced Studies.

42. R. W. Heckel and H. W. Paxton: Trans. AIME, 1960, 218, 799 806

43. R. W. Heckel, J. H. Smith and H. W. Paxton: Trans. AIME, 1960 218, 566-568.

44. H. I. Aaronson and C. Wells: Trans. AIME, 1956, 206, 1216 1223

45. H. I. Aaronson: in 'The mechanism of phase transformations in metals, Vol. 18, 'Effects of nucleation site upon precipitate morphology', 47-56; 1956, London, The Institute of Metals.

46. H. I. Aaronson, G. Spanos, R. A. Masumura, R. G. Vardiman, D. W. Moon, E. S. K. Menon and M. G. Hall: Mater. Sci. Eng. B, 1995, B32, 107-123

47. S. W. Thompson and P. R. Howell: Scripta Metall., 1987, 21, 1353-1357.

48. S. W. Thompson and P. R. Howell: Proc. Solid-solid Phase Transformations, (eds. W. C. Johnson et al.), 1127-1132; 1994, Warrendale, PA, TMS

49. G. Spanos and H. I. Aaronson: Acta Metall., 1990, 38, 2721-2732.

50. A. A. Bataev, V. A. Bataev, S. A. Kotorov, P. V. Ilyushenko and A. I. Popeylyukh: Phys. Metal. Metall., 1998, 85, 678-681.
51. M. A. Mangan and G. J. Shiflet: Proc. Solid-solid Phase Transformations, (eds. W. C. Johnson et al.), 547-552; 1994, Warrendale, PA, TMS

52. H. Wieland, T. N. Rouns and J. Liu: Z. Metallkd., 1994, 85, $592-$ 597.

53. S. A. Cowley and D. V. Edmonds: Proc. Phase Transformations 87, (ed. G. W. Lorimer), 459; 1988, London, The Institute of Metals.

54. H. Warlimont: Trans. TMS-AIME, 1962, 224, 485-499.

55. F. A. Khalid and D. V. Edmonds: Acta Metall. Mater., 1993, 41, 3421-3434.

56. F. A. Khalid and D. V. Edmonds: Metall. Trans. A, 1993, 24A, 781-793.

57. K. H. Yang and W. K. Choo: Acta Metall. Mater., 1994, 42, $263-$ 269.

58. J. M. Howe and G. Spanos: Philos. Mag. A., 1999, 79A, 9-30.

59. J. E. Krzanowski and S. J. Hruska: Scripta Mater., 1987, 21, 39 44.

60. M. V. Kral, M. A. Mangan, G. Spanos and R. O. Rosenberg: Mater. Charact., 2000, 45, 17-23.

61. C. S. Barrett, A. H. Geisler and R. F. Mehl: Trans. AIME, 1941, 143, 134

62. A. Carter: J. Inst. Met., 1955, 83, 481.

63. J. R. Bradley and H. I. Aaronson: Metall. Trans. A, 1977, 8A, 317.

64. E. B. Hawbolt and L. C. Brown: Trans. AIME, 1967, 239, 19161924.

65. T. Ando and G. Krauss: Metall. Mater. Trans. A, 1981, 12A, 1283-1290.

66. T. Ando and G. Krauss: Proc. Int. Conf. on 'Solid-solid phase transformations, (eds. H. I. Aaronson et al.), 573-577; 1982, Warrendale, PA, TMS-AIME.

67. J. A. Wasynczuk, R. M. Fisher and G. Thomas: Metall. Trans. A, 1986, 17A, 2163-2173.

68. A. Hultgren: Jernkontorets Ann., 1951, 135, 403.

69. A. Hultgren: Kgl. Svenska Vetenskapsakad. Handl., 1953, 4.

70. W. Z. Zhang, F. Ye, C. Zhang, Y. Qui and H. S. Fang: Acta Mater., 2000, 48, 2209-2219.

71. W. Z. Zhang and G. R. Purdy: Phil. Mag. A, 1993, 68A, 279

72. W. Z. Zhang and G. R. Purdy: Phil. Mag. A, 1993, 68A, 291.

73. C. S. Barrett and T. B. Massalski: 'The structure of metals', 3rd edn; 1980, New York, Pergamon Press.

74. H. I. Aaronson: in 'The mechanism of phase transformations in crystaline solids', 270-281; 1969, London, The Institute of Metals.

75. J. S. Bowles and C. S. Barrett: Prog. Met. Phys., 1952, 3, 1.

76. U. Dahmen: Acta Metall., 1982, 30, 63.

77. H. I. Aaronson, T. Furuhara, J. M. Rigsbee, W. T. Reynolds-Jr and J. M. Howe: Metall. Trans. A, 1990, 21A, 2369.

78. S. A. Hackney and G. J. Shiflet: Acta Metall., 1987, 35, 1019.

79. M. G. Hall, H. I. Aaronson and K. R. Kinsman: Surf. Sci., 1972, 31, 257.

80. J. M. Rigsbee and H. I. Aaronson: Acta Metall., 1979, 27, 365376.

81. J. M. Rigsbee and H. I. Aaronson: Acta Metall., 1979, 27, 351.

82. F. Ye and W. Z. Zhang: Acta Mater., 2002, 50, 2761-2777.

83. W. Bollmann: 'Crystal defects and crystalline interfaces'; 1970, New York, Springer Verlag.

84. W. Bollmann: 'Crystal lattices, interfaces, matrices'; 1982, Geneva, Bollmann.

85. R. Bonnet and F. Durand: Phil. Mag. A, 1975, 32A, 997.

86. R. W. Bulluffi, A. Brokman and A. H. King: Acta Metall., 1982, 30, 1453.

87. R. W. Fonda, W. T. Reynolds-Jr and M. V. Kral: Symposium on Austenite Formation and Decomposition at Materials Science and Technology 2003, (eds. E. B. Damm and M. J. Merwin), 425436; 2003, Warrendale, PA, TMS

88. Q. Liang and W. T. Reynolds-Jr: Metall. Mater. Trans. A, 1998, 29A, 2059-1072.

89. W. T. Reynolds-Jr, J. F. Nei, W. Z. Zhang, J. M. Howe, H. I. Aaronson and G. R. Purdy: Scripta Mater., 2003, 49, 405- 409.

90. M. V. Kral and R. W. Fonda: Scripta Mater., 2000, 43, 193-198.

91. A. T. Davenport and R. W. K. Honeycombe: Proc. R. Soc. Lon. A, 1971, 322A, 1971 .

92. R. W. K. Honeycombe: Metall. Trans. A, 1976, 7A, 915-936.

93. R. W. K. Honeycombe: 'in 'Phase transformations in ferrous alloys', (ed. A. R. Marder and J. I. Goldstein), 259-280; 1984, Warrendale, PA, TMS-AIME.

94. T. Obara, G. J. Shiflet and H. I. Aarosnon: Metall. Trans. A, 1983, 14A, 1159-1167.

95. G. Spanos, W. T. Reynolds-Jr and R. A. Vandermeer: Metall. Trans. A, 1991, 22A, 1367-1380. 
96. C. Zener: Trans. AIME, 1946, 167, 550-595.

97. M. Hillert: Jernkont. Ann., 1957, 141, 757-789.

98. W. P. Bosze and R. Trivedi: Acta Metall., 1975, 23, 713-722.

99. E. P. Simonen, H. I. Aaronson and R. Trivedi: Metall. Trans., 1973, 4, 1239-1245

100. R. Trivedi and G. M. Pound: J. Appl. Phys., 1967, 38, 3569-3576.

101. R. Trivedi: Metall. Trans., 1970, 1, 921-927.

102. R. Trivedi: Proc. Int. Conf. on 'Solid-solid phase transformations', (eds. H. I. Aaronson et al.), 477-502; 1982, Warrendale, PA, TMS-AIME.

103. M. Enomoto: Acta Metall., 1987, 35, 947-956.

104. M. Enomoto: Acta Metall., 1987, 35, 935-945.

105. W. S. Owen: J. Iron Steel Inst., 1951, 167, 117-120.

106. C. Atkinson: Proc. R. Soc. A, 1982, 384A, 107-133.

107. K. R. Kinsman, E. Eichen and H. I. Aaronson: Metall. Trans. A, 1975, 6A, 303-317.

108. C. Laird and H. I. Aaronson: Acta Metall., 1969, 17, 505-519.

109. S. Elangovan and M. R. Plichta: Scripta Metall., 1986, 20, 575580.

110. R. M. Aichen-Jr and M. R. Plichta: Proc. Phase Transformations 87, (ed. G. W. Lorimer), 504-506; 1988, London, The Institute of Metals.

111. R. W. Fonda and M. V. Kral: Proc. Microscopy \& Microanalysis, 342-343; 2000, San Fancisco, CA, San Francisco Press.

112. J. P. Hirth, R. G. Hoagland and R. J. Kurtz: Metall. Mater. Trans. A, 1998, 29A, 2033-2038.

113. D. E. Coates: Metall. Trans., 1972, 3, 1203-1212.

114. D. E. Coates: Metall. Trans., 1973, 4, 2313-2325.

115. D. E. Coates: Metall. Trans., 1973, 4, 1077-1086.

116. H. I. Aaronson, W. T. Reynolds-Jr and G. R. Purdy: Metall. Mater. Trans. A, 2004, 35A, 1187-1210.
117. S. S. Babu, K. Hono and T. Sakurai: Metall. Mater. Trans. A, 1994, 25A, 499-508.

118. G. Ghosh, C. E. Campbell and G. B. Olson: Metall. Mater. Trans. A, 1999, 30A, 501-512.

119. B. P. J. Sandvik: Metall. Trans. A, 1982, 13A, 789800 .

120. G. Spanos, H. S. Fang and H. I. Aaronson: Metall. Trans. A, 1990, 21A, 1381-1390.

121. G. Spanos: Metall. Trans. A, 1994, 25A, 1967-1980.

122. H. I. Aaronson, G. Spanos and W. T. Reynolds-Jr: Scripta Mater., 2002, 47, 139-144

123. B. P. J. Sandvik: Proc. Int. Conf. on 'Solid-solid phase transformations', 1023-1027; 1982, Warrendale, PA, TMSAIME.

124. B. P. J. Sandvik and C. M. Wayman: Metall. Trans. A, 1983, 14A, 823-834.

125. C. M. Wayman: in 'Phase transformations in ferrous alloys', (ed. A. R. Marder and J. I. Goldstein), 49; 1984, Warrendale, PA, TMS-AIME.

126. C.-Y. Hung, G. Spanos, R. O. Rosenberg and M. V. Kral: Acta Mater., 2002, 50, 3781-3788

127. G. Spanos, C.-Y. Hung and M. V. Kral: Proc. 4th Int. Conf. on 'Processing and manufacturing of advanced materials', (eds. T. Chandra et al.), 1599-1604; 2003, Enfield, NH, Trans. Tech. Publications Ltd

128. J. W. Cahn: Acta Metall., 1956, 4, 449.

129. W. F. Lange and H. I. Aaronson: Metall. Trans. A, 1979, 10A, 1951-1952.

130. T. Furuhara and H. I. Aaronson: Acta Metall. Mater., 1991, 39 , 2887-2899. 